Article

\title{
Modelling and Evaluation of Waste Heat Recovery Systems in the Case of a Heavy-Duty Diesel Engine
}

\author{
Amin Mahmoudzadeh Andwari ${ }^{1,2, *(\mathbb{C})}$, Apostolos Pesyridis ${ }^{1}{ }^{(\mathbb{O}}$, Vahid Esfahanian ${ }^{2}$, \\ Ali Salavati-Zadeh ${ }^{3}$ (D) and Alireza Hajialimohammadi ${ }^{4}$ \\ 1 Centre for Advanced Powertrain and Fuels Research (CAPF), Department of Mechanical, Aerospace and \\ Civil Engineering, Brunel University London, London UB8 3PH, UK; a.pesyridis@brunel.ac.uk \\ 2 Vehicle, Fuel and Environment Research Institute (VFERI), School of Mechanical Engineering, \\ College of Engineering, University of Tehran, Tehran 1439956191, Iran; evahid@ut.ac.ir \\ 3 Niroo Research Institute (NRI), Tehran 1468613113, Iran; asalavatizadeh@nri.ac.ir \\ 4 Mechanical Engineering Department, Semnan University, Semnan 3513119111, Iran; ahajiali@semnan.ac.ir \\ * Correspondence: amin.mahmoudzadehandwari@brunel.ac.uk; Tel.: +44-(0)-1895-267901
}

Received: 3 March 2019; Accepted: 26 March 2019; Published: 11 April 2019

check for updates

\begin{abstract}
In the present study, the effects of Organic Rankine Cycle (ORC) and turbo-compound (T/C) system integration on a heavy-duty diesel engine (HDDE) is investigated. An inline six-cylinder turbocharged 11.5 liter compression ignition (CI) engine employing two waste heat recovery (WHR) strategies is modelled, simulated, and analyzed through a 1-D engine code called GT-Power. The WHR systems are evaluated by their ability to utilize the exhaust excess energy at the downstream of the primary turbocharger turbine, resulting in brake specific fuel consumption (BSFC) reduction. This excess energy is dependent on the mass flow rate and the temperature of engine exhaust gas. However, this energy varies with engine operational conditions, such as speed, load, etc. Therefore, the investigation is carried out at six engine major operating conditions consisting engine idling, minimum BFSC, part load, maximum torque, maximum power, and maximum exhaust flow rate. The results for the ORC and $\mathrm{T} / \mathrm{C}$ systems indicated a $4.8 \%$ and $2.3 \%$ total average reduction in BSFC and also maximum thermal efficiencies of $8 \%$ and $10 \%$, respectively. Unlike the ORC system, the $\mathrm{T} / \mathrm{C}$ system was modelled as a secondary turbine arrangement, instead of an independent unit. This in turn deteriorated BSFC by $5.5 \%$, mostly during low speed operation, due to the increased exhaust backpressure. It was further concluded that the T/C system performed superiorly to the ORC counterpart during top end engine speeds, however. The ORC presented a balanced and consistent operation across the engines speed and load range.
\end{abstract}

Keywords: waste heat recovery; Organic Rankine Cycle; turbo-compound; brake specific fuel consumption; engine thermal efficiency

\section{Introduction}

In recent years, the growing worldwide population and industrial development has seen an equally increasing demand in energy. The internal combustion engine (ICE) has, by far, grown to be the most popular means of transport since the second half of the 20th century. Unfortunately, a typical ICE will only manage to convert approximately $30-35 \%$ of the total provided chemical energy into effective mechanical work, as illustrated in Figure 1 [1-6]. 


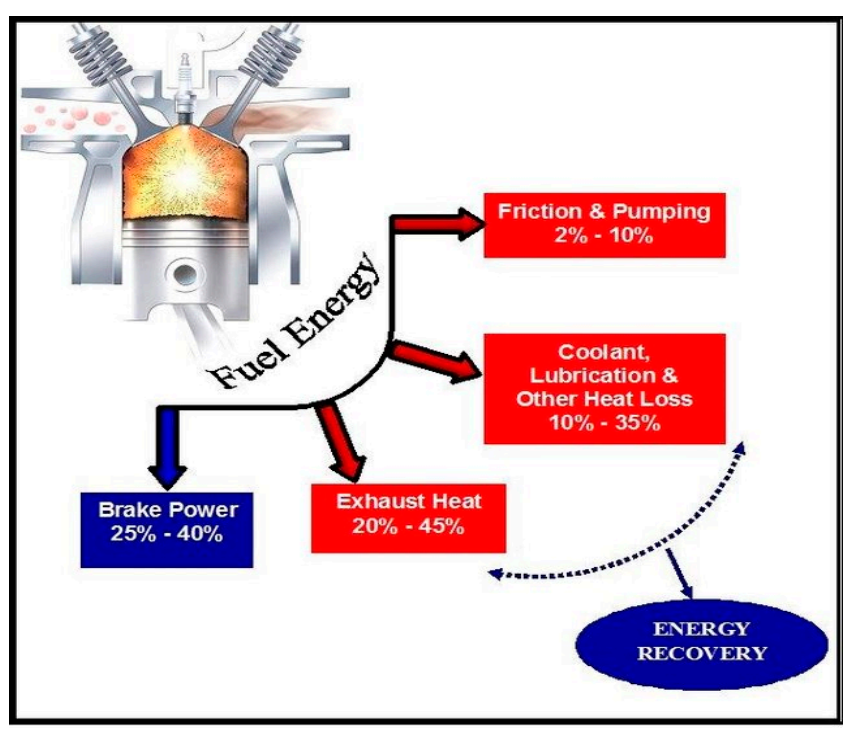

Figure 1. Variation total fuel energy content in ICE.

As with any system that produces work in real life, it is very challenging to achieve an adiabatic process during which thermal expansion occurs. Even in present ICEs, approximately $60-70 \%$ of the energy discharged by the fuel is wasted predominately in the form of heat [7-13]. During the last two decades, typical engine specific power output ratios are in the region of 1.5. At the same time, emission levels have reached a factor of 10. This is mainly due to the restrictions imposed by EURO, forcing technology to progress in the production of cleaner and more efficient ICE [14-20]. Even a conventional turbocharger only takes advantage of a portion of the exhaust gas energy in the shape of kinetics and pressure, which constitutes a fraction of the energy losses in a naturally aspirated engine. The biggest percentage is heat transfer and exhaust gas enthalpy dissipation, which is accountable for about $50-85 \%$ of the outstanding low heating values of the utilized fuel [21-25]. As a result, presently, waste heat recovery (WHR) has been the primary concentration point of research and development departments of engine manufacturers. This is due to the considerable potential energy amount that can be recovered in the form of heat [26-28]. Modern WHR systems amongst others include the following:

- Mechanical turbo-compounding

- Electrical turbo-compounding

- Thermoelectric generators (TEG)

- Steam Rankine cycle

- $\quad$ Organic Rankine cycle (ORC)

- Brayton thermodynamic cycle

All of the above can recover a segment of the exhaust gas energy and can subsequently enhance the engines' thermal efficiency. They all operate on relatively similar thermodynamic principles, but not all of them perform in the same fashion. The beginning of research and development on the feasibility of the Rankine cycle system as a WHR method dates back to the 1970's [29-32]. The fundamental orientation of the studies has been the thermal optimization of heavy duty diesel engines (HDDE) due to their high thermal efficiency potential, ranging, by todays' standards, between $40-45 \%$ [33-36]. This makes HDDE the most favorable candidates, as a 10-15\% improvement in fuel efficiency is not uncommon for ORC applications [37-40]. The high thermal efficiency figures have also influenced industries to make use of HDDE, with power outputs of up to $600 \mathrm{~kW}$ for on and off-highway commercial vehicles. Typical engine displacements vary between 6-12 liter with multiple cylinder numbers and configurations, while the latest era of HDDE, utilizing high-pressure common rail direct injection systems, reach pressures of over 2500 bar. Part of the reason for this high efficiency is the use 
of forced induction. Forced induction constitutes a method of increasing engine power output that dates back to the late nineteenth and early twentieth century [41-45].

Supercharging an engine can be done both by either mechanical and/or chemical means. Power output is directly proportional to the mass of fuel and air burned inside the engines' cylinders. To ncrease fuel mass delivery, one must first increase air mass intake to avoid continuous combustion of rich mixture. Additional air supplying components that are gear and belt driven are normally called superchargers or blowers. Turbocharging is when the supercharger is driven by the engines' hot exhaust gases. One of the reasons forced induction became so popular over the past decades, other than the significant performance gains, is because it was a clever way of benefiting from the energy of burned exhaust gas residue that would otherwise be wasted. As a result, the automotive industry perceived it to be an acceptable mix of cost, performance, fuel economy, and reliability [40,46-48]. In turbocharged engines, heat transfer is a very complex entity, which greatly affects turbocharger performance, efficiency, and selection. As exhaust gas flows through the turbine, the turbine housing absorbs a sizable percentage of the total enthalpy by forced convection, due to the temperature difference between the walls and exhaust gases. This heat is then lost to the environment by means of radiation. Heat transfers by forced convection are also evident on the turbine wheel blades, shaft, and, subsequently, on the lubricant because of the exhaust gas expansion [49-54]. On the other hand, the compressor side acts as a heat sink and is subject to heat conduction derived through the bearing and/or turbine housings as well as the engine itself. This heat flux is inbound and may affect the temperature and pressure of the inducted air at low rotating speeds and compression ratios $[55,56]$. It was discovered that despite past research on WHR using primarily ORC and T/C systems either of mechanical or electrical nature, there is limited information on the comparison of the two systems, which are assessed in this research [1,36,57-59]. This study aims to identify which of the two adopted WHR methods (ORC and T/C) performs in a better manner in terms of improving engine thermal efficiency and BSFC by means of 1-D engine simulation software.

\subsection{Waste Heat Recovery}

Almost $60 \%$ to $70 \%$ of the chemical energy provided to the engine in the form of fuel is wasted, mostly from rejected heat. In a system that carries out work, heat loses are inevitable due to the first law of thermodynamics. The most arbitrary heat loses are that of the exhaust and cooling systems, but losses can also be on behalf of pumping losses, internal friction, drivetrain slippage, and other accessories. In fact, during in-town driving a typical vehicle will utilize, on average, only about $13 \%$ of the actual fuel energy to propel forward. To put it into context, a diagram presenting the energy pathway is located in Figure 2. Fortunately, developed technologies allow the conversion of a percentage of waste heat back to usable energy via several harvesting systems. Automobiles and especially heavy-duty commercial on and off highway vehicles have under scrutiny been lately $[20,60,61]$.

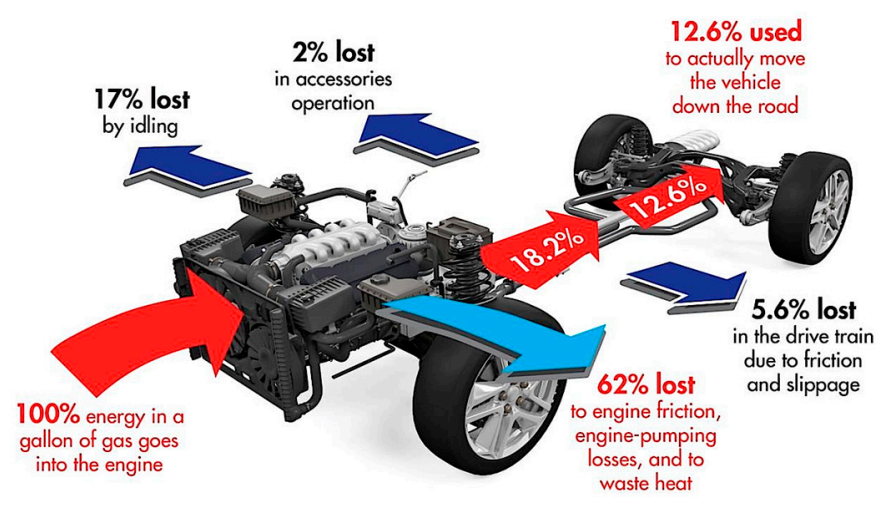

Figure 2. Typical city driving energy pathways. 
In the US alone, tractor trailers, delivery vans, garbage trucks, and more are expected to reduce $25 \%$ of their exhaust emissions by 2027 , with a potential to avoid up to 1.1 billion metric tons of carbon dioxide emissions. Many automotive industries that design and manufacture WHR systems seem to avoid mentioning the disadvantages of these promising devices. For example, they tend to incur an increase in exhaust backpressure, which has a direct impact on engine fuel consumption. Not many preliminary studies can be found that take exhaust backpressure fluctuation caused by the heat exchanger or turbine into account. As a result, the comprehension data, in consideration of designing and optimizing the components, is very limited. Another negative aspect is that integrated WHR units come alongside a weight penalty. The additional inertia will inevitably cause further fuel consumption and, subsequently, an increase in BSFC. These drawbacks are easy to neglect when heat harvesting percentages and thermal efficiencies of WHR means as well as the power unit are the center of attraction of the investigation $[20,62,63]$.

\subsection{Steam/Organic Rankine Cycle}

The Rankine cycle (RC) is considered an ideal cycle for vapor power plants. It is comprised by four primary components, a pump, a boiler/evaporator, a power expansion turbine, and a condenser. The pump begins the cycle by pumping the working fluid through the system. The evaporator or boiler applies the recovered waste heat on the fluid, thus raising its temperature and pressure, creating (in some cases) superheated steam. The fluid is then expanded in the turbine utilizing the built up temperature and pressure by generating power through a shaft. The process is continued by the condenser, which condenses the vapor back to liquid form ready to be pumped again for another cycle $[6,64,65]$.

The actual and ideal thermodynamic evaluation of the Rankine cycle operations can be slightly different from each other. In an ideal RC system, the compression and expansion processes in the pump and turbine, respectively, are considered isentropic. In an identical trend, the heat addition and heat rejection processes in the evaporator and condenser, respectively, are regarded as constant. This transliterates these processes as internally reversible. A reversible process is the process that can be reversed without leaving any traces to the environment or surroundings. Since the pump, evaporator, turbine, and condenser are all steady-flow components, the RC can be analyzed as a closed loop, steady-flow process following the steady-flow energy equation. This in turn implies that no heat engine will have a thermal efficiency of $100 \%$ because there must be a low temperature sink for the heat to be transferred to. In addition, the actual RC system suffers from losses throughout the systems cyclic function such as friction losses, piping losses, and heat transfer to surroundings. All of these losses cause an irreversible increase in entropy $[2,9,10,32]$.

\subsection{Organic Rankine Cycle and Internal Combustion Engines}

The only difference between the conventional RC and the organic Rankine cycle (ORC) is the substance which circulates within the system. A traditional $\mathrm{RC}$ is known for using $\mathrm{H}_{2} \mathrm{O}$ (water) as a working fluid. In the case of ORC, the operating fluid is an organic liquid element accompanied by a greater molecular mass and reduced boiling point compared to that of $\mathrm{H}_{2} \mathrm{O}$. These alternative working fluids can demonstrate a number of thermodynamic benefits as they allow the system to operate by using downsized temperatures. Consequently, the operation of the ORC results in greatly reduced thermal efficiency readings owning to the lower temperature transactions. However, this also has a positive impact on the total operational cost, as far less heat energy is required to produce a given power. The promising potential of low and moderate heat operation is the primary reason the ORC has grown to be popular amongst automobile industry research and development departments.

This WHR method, however, is not limited to ICE applications, but is also utilized by a number of other heat rejecting machinery, such as geothermal plans, solar thermal systems, and biomass plants, as well as industrial processes. The unstable transient and remarkably variable operational profiles of automotive vehicles make it more demanding to implement ORC systems and, therefore, the technology 
is expected to hit the market around 2020. This is mainly due to the non-existent control methods and instruments, which are of great necessity for the safety, performance, reliability, and durability of the power unit and ORC. Correspondingly, ORC patents are primarily developed and promoted for immobilized power production units as well as marine purposes [41,44,48,62]. In an investigation of an ORC system for a heavy-duty truck application and a passenger-car application, a 3.4\% estimated reduction in fuel consumption was obtained. This was the result of a turbine efficiency of $58 \%$, after the custom blade was designed on CFD software specifically for the employed ORC system. During the analysis of a diesel-Rankine cycle combination in a different HDDE case [58], it was concluded that during full load conditions (BMEP $=2 \mathrm{Mpa}$ ) a BSFC reduction of $2.6-3 \%$ was possible. The values of the temperature, pressure and, working fluid flow rate were all estimated by the thermodynamic characteristics of the multifarious utilized substances, namely, water $\left(\mathrm{H}_{2} \mathrm{O}\right)$, methanol $(\mathrm{MeOH})$, toluene (PhMe), pentafluoropropane (R245fa), and tetrafluoroethane (R134a). Moreover, the performance of an ORC system by integrating the WHR system on a $15 \mathrm{~L}$ diesel engine was investigated. The simulation assessment was performed by gathering the turbine shaft power from the exhaust enthalpy during steady-state operation. The use of dual finned heat exchangers with identical dimensions and properties was implemented in a parallel sequence after the turbocharger turbine to collect waste energy. The total power output of the engine was increased by an estimated 5\%, while the engines' pumping losses were kept at a maximum total of $4 \mathrm{~kW}$. It was also supported that much research based on WHR seem to neglect circumstantial disadvantages. Investigations based on ORC are no exception, with a couple of crucial unmentioned performance characteristics. These include the effect of refrigerant flow rate on ORC performance as well as the effects of pressure drops through the heat exchangers, with the resulting parasitic flow-work losses, two negative aspects which are overcompensated considering that the average theoretical integrated vehicle ORC system yields an increase in thermal efficiency of about 6-15\%. As far as ORC fitment is concerned, depending on packaging and weight limitations of the given vehicle, the ORC recovery method can include multiple supplementary components. Typical layout implementations of ORC systems to HDDE can include twin parallel or in-series evaporators, individual for the exhaust and EGR valve. Furthermore, the introduction of a recuperator has found its way into the system due to the possibility of ORC efficiency increments. It is typically positioned between the turbine and the condenser and its functionality is to recuperate some of the heat before it is released to the heat sink by the condenser. Preheating the working substance with the aid of a charge air cooler (CAC) also constitutes an investigation possibility. Other researchers suggest replacing current engine block cooling techniques with ORC working fluids to take advantage of the additional waste heat and improve power regeneration. On the other hand, all of these efforts and aspects tend to increase the systems complexity rather than provide considerable ORC gains. Hence, a straightforward simplistic ORC composition is a more appealing solution for vehicle integration than most $[6,40,44,65,66]$.

\subsection{Engine Turbocompounding}

In a conventional turbocharger, the engines' exhaust gas heat and airflow energy is harvested by a turbine, which is connected to a compressor through a common shaft. In the compressor side, air is induced and pressurized in the intake manifold, which increases the total power output of the engine with a small penalty on exhaust backpressure. A Turbo-compounding (T/C) system operates in a similar fashion, with the only difference being that there is no compressor at the end of the turbine shaft. The $\mathrm{T} / \mathrm{C}$ turbine would be typically placed at the outlet of the primary turbine, therefore being driven by the leftover energy, translating it into a torque. T/C is a potentially prosperous WHR method, which can either be of a mechanical or electrical nature. A T/C system is a relatively less complicated arrangement compared to the ORC and this could potentially result in a lower unit production cost and a lighter component all together. On the other hand, one of the primary disadvantages of $\mathrm{T} / \mathrm{C}$ implementation is the increment of engine backpressure and pumping losses, even more so than the ORC systems' heat exchanger. Exhaust backpressure is directly proportional to cylinder pumping loses. Hence, during meager engine speeds and loads, the total engine brake power output is prone to suffer. 
As mentioned before, the power produced from the turbine can be manipulated either electrically or mechanically $[10,14,30,67]$.

\subsubsection{Electrical Turbo-Compounding}

In an electric $\mathrm{T} / \mathrm{C}$ system, an alternator/stator converts the turbines' rotational shaft power into electrical power. This electricity then either returns to the main battery to be stored for later usage or is immediately effective to operate various engine/vehicle components such as the starter motor, headlights, etc. Another possibility is the integration of an electrical compressor acting as a supercharger to assist the vehicles acceleration during low engine speeds where turbo-lag is yet to be overcome. Furthermore, the function of an electric motor directly mounted to the engines' crankshaft can also assist engine operation. Apart from throttle response, the techniques described can additionally improve fuel economy. In fact, in an electric $\mathrm{T} / \mathrm{C}$ system, the estimated indication of reduction in fuel consumption ended up being a maximum of $10 \%$. In addition, the strategy of the motor to crankshaft scheme seemed to enhance drivability and engine flexibility during transient periods. This in turn decreased exhaust gas emissions for an altogether greener engine activity. One of the other main advantages of electrical turbo-compounding is the space saving characteristics. Whether it is implemented as an integrated unit or a separate turbo-generator, it is a neat and tightly packaged component compared to the mechanical T/C system. On the other hand, the downside in the fitment of the electric $\mathrm{T} / \mathrm{C}$ system is that it would generally require modifications to the existing turbomachinery $[2,6,13,49,64]$. This means that the already implemented turbocharger would have to be customized to incorporate the addition of a stator and rotor doublet in-between the turbine and the compressor impellers. However, there is the possibility that the electrical system is mounted on a separate turbine downstream of the main power turbine, also called a turbo-generator. This would diminish the need for existing turbo modifications because it is an independent and standalone unit.

\subsubsection{Mechanical Turbo-Compounding}

Similarly, the mechanical T/C system operates again by the addition of a secondary power turbine mounted sequentially after the principal turbine, to scavenge the surplus energy. The generated power is afterwards transmitted, via a shaft, through a gearbox unit followed by a mechanical coupling to the power units' crankshaft. It is generally a low volume and production cost system thus it is fundamentally applicable for medium and heavy-duty diesel power units. These leading HDDE manufacturers have been investigating the effects of different $\mathrm{T} / \mathrm{C}$ arrangements with satisfactory results, namely a typical reduction in BSFC on a scale ranging between 3-6\%. Investigations proved that the total improvement in incremental fuel consumption strictly due to the turbo-compounding action was a $4.2 \%$ to $5.3 \%$ estimate depended upon the terrain or mission load factor. Incorporating a mechanical $\mathrm{T} / \mathrm{C}$ system in favor of an 11 Liter 6 cylinder turbocharged diesel engine resulted in a total of $5 \%$ reduction in BSFC during full load operation [42,43,45].

\section{Engine Waste Heat Recovery System Modelling}

In this section, the methods and tools used to assess the effects of a T/C system against the effects of an integrated ORC are explained. Important performance parameters, such as BSFC, thermal efficiency, power output, and overall fuel consumption are monitored and examined in conjunction with two WHR methods. The same virtual turbocharged HDDE was utilized for both the adopted techniques in favor of result accuracy. The $\mathrm{T} / \mathrm{C}$ system was regarded as a secondary turbine arrangement downstream of the primary power turbine. With the aid of 1-D computer software (GT-Power), the engine, ORC, and $\mathrm{T} / \mathrm{C}$ systems are modelled and optimized via trial and error simulations.

\subsection{Engine Modelling and Calibration}

An in-line, 6 cylinder, 11.5 liter, and turbocharged HDDE is assumed as a base research engine. The engine's major specifications are presented in Table 1. Figure 3 illustrates the engine model 
developed in GT-Power. The engine model is the same validated engine model as featured in Karvountzis-Kontakiotis et al [58], presented at the SAE World Congress. The model was further modified, in addition to ORC, to be able to simulate turbo-compounding operation.

Table 1. Modelled engine specifications.

\begin{tabular}{lc}
\hline Specification & Value \\
\hline Engine Type & In-line 6, 4-Stroke, Diesel CI, Common Rail \\
Bore $\times$ Stroke & $130 \times 144(\mathrm{~mm})$ \\
Displacement & $11.5(\mathrm{~L})$ \\
Compression Ratio & $19: 1$ \\
Max Power & $478.3[\mathrm{~kW}] @ 2500 \mathrm{RPM}$ \\
Max Torque & $1850[\mathrm{~N} \cdot \mathrm{m}] @ 2050 \mathrm{RPM}$ \\
BSFC at Peak Efficiency & $214.7[\mathrm{~g} / \mathrm{kW} \cdot \mathrm{h}]$ \\
RPM Range & $850-2600$ \\
\hline
\end{tabular}

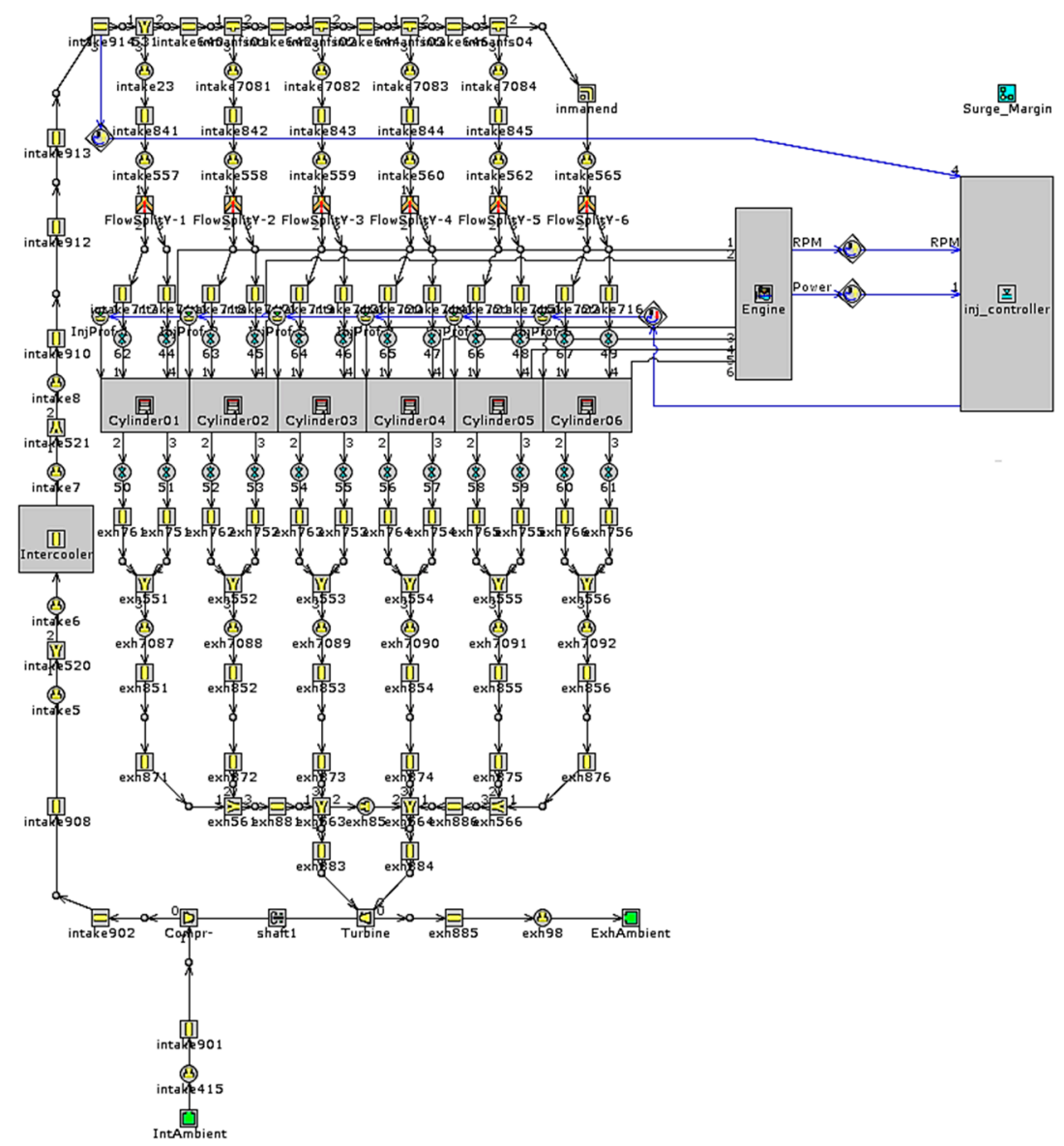

Figure 3. Engine model in GT-Power software.

A typical modern direct injection diesel engine is capable of working over a speed range of $600 \mathrm{rpm}$ to $2600 \mathrm{rpm}$. This speed range is larger than normal but allows the data presented to be used over any part of that range. Therefore, the engine model was operated through 36 different cases ranging from $850 \mathrm{rpm}$ to $2600 \mathrm{rpm}$ using $50 \mathrm{rpm}$ increments for a better result accuracy. It was decided that the best way to approach the optimization process was to limit the number of variables. This task proved to be challenging because, apart from engine speed, the operational cases varied in terms of engine load, fuel mass flow rate, power target of injector controller, turbine speed, etc.

A solid baseline of results was achieved by running the two WHR rivals at operating points, which the engine spends most of its working time. Figure 4 presents the typical engine speed and 
torque time percentage distribution for a crawler loader. The engine tested during this task is the type of engine that could be used for similar off-highway vehicles, as in Figure 4.

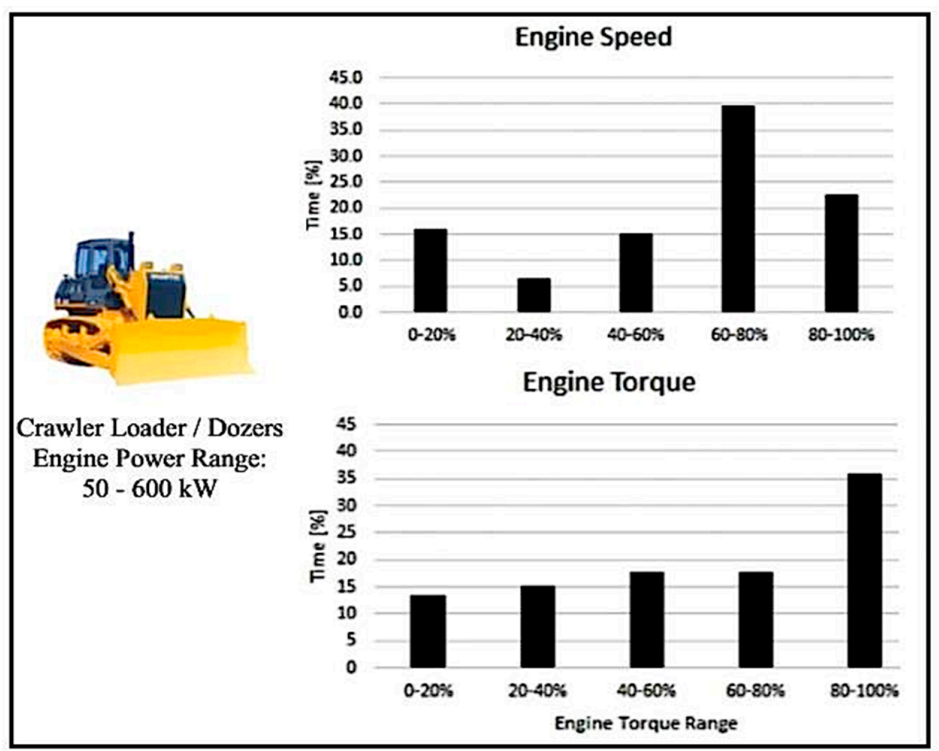

Figure 4. Typical HDDE time operational profiles.

In order to identify the ideal benchmarks in which the WHR systems will be constructed, optimized, and simulated, it is critical to run the engine simulation under real-life operating circumstances. In general, these optimum operational points are where the power unit produces certain usable benefits, such as maximum exhaust gas flow rates, lowest BSFC etc. Therefore, emphasis has been given to these points, which resemble an operation this engine is most likely to have under a typical working condition, similar to the example illustrated in Figure 4. Therefore, the WHR systems are assessed and compared for 6 dominant engine functioning points, which are determined by the calibration process. These include running at idling, ideal BSFC, part load, maximum torque output, maximum brake power output, and maximum exhaust flow rate. These are denoted by $\mathrm{X} 1, \mathrm{X} 2, \mathrm{X} 3, \mathrm{X} 4, \mathrm{X} 5$, and $\mathrm{X} 6$ respectively. As a gauge, the obtained baseline engine specifications are plotted using GT-Power 2-D graphical representations. This includes the BSFC contour map, which also indicates individual BMEP readings as well as power versus torque curves, all plotted in Figures 5 and 6 respectively. For the engine assessment, performance parameters, and comparison accuracy, both WHR methods are implemented on the same engine model.

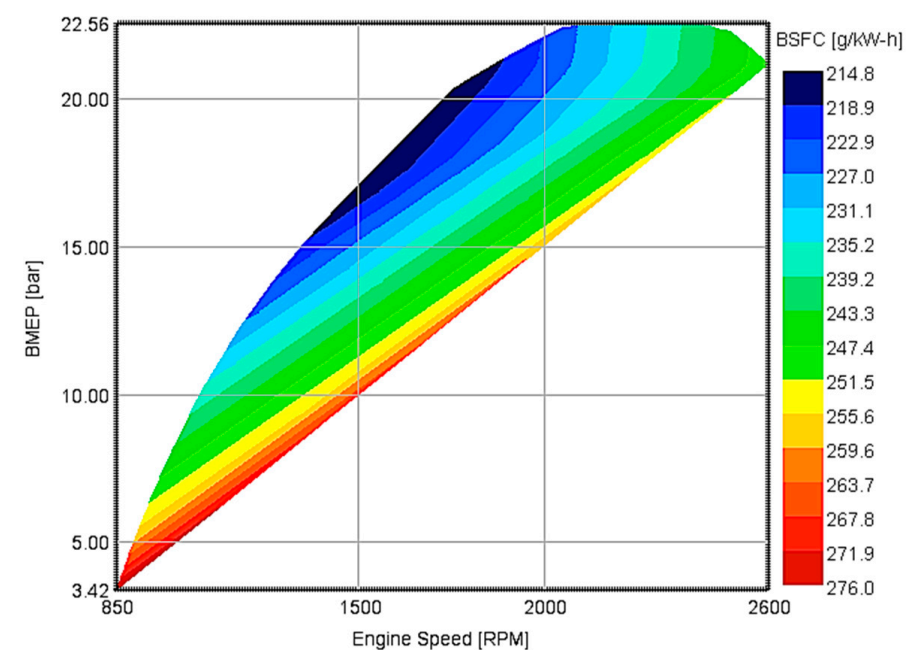

Figure 5. Baseline BSFC contour map. 


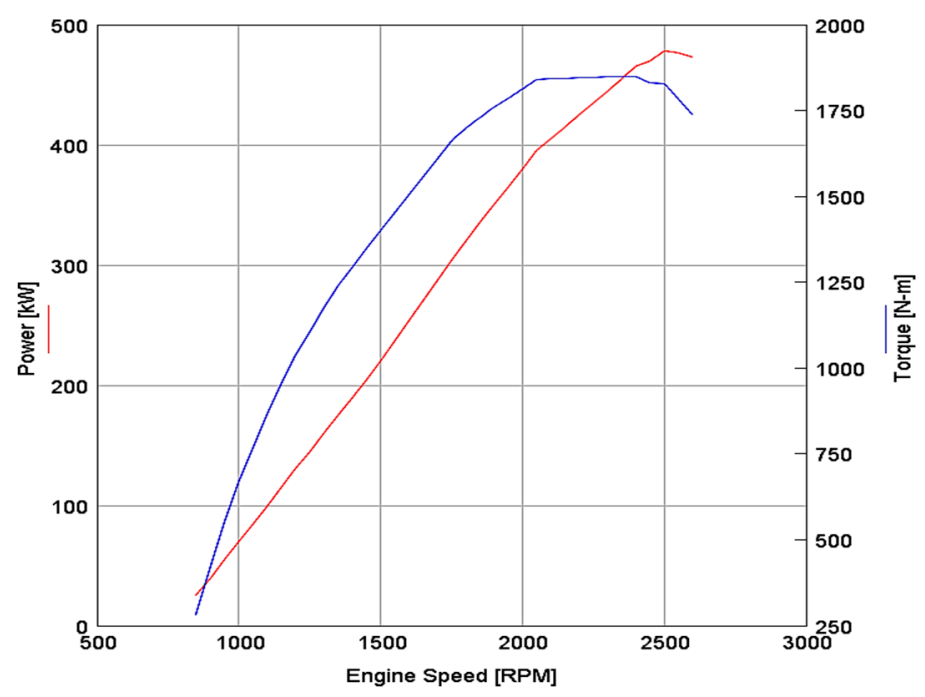

Figure 6. Baseline Power vs. Torque.

\subsection{ORC System Modelling}

The ORC system model is created and optimized in GT-Power software according to the predetermined aims and objectives of the study. The ORC model was kept to a minimal level and thus consisted of the following four main components: The pump, the boiler/evaporator, the expansion turbine, and the condenser. The pump and turbine elements were each coupled to a speed governor that sets the speed for each case run. These speed governors allowed turbine and pump speed variations for each operational point and, as explained later, this proved to be of significant value for the determination of the individual points' maximum performance enhancement. However, an increase in pump speed provokes an increase in work input requirement. Thus, to accomplish positive results, the energy recovered by the system will have to unavoidably reimburse the energy cost necessary for the pump operation.

The amount of energy deducted by the pump has a direct impact on the ORC system's efficiency due to the following relation. Another important factor which greatly interferes with the efficiency of the ORC system is the working fluid, so the refrigerant of type R245fa (Pentafluoropropane) is selected due to its advantageous low temperature heat recovery characteristics. The model of ORC system setup is illustrated in Figure 7. The control volume was considered to be adiabatic and, therefore, during all processes there was no heat escaping through the walls and surrounding features. This signifies that the exhaust gas pressure and temperature at the inlet and outlet of the evaporator were equal. Similarly, the coolant pressure and temperature at the inlet and outlet of the condenser are kept at an equal value. The next step is implementing the engines' turbocharger turbine outputs as ORC inputs at the heat exchanger. That includes the exhaust gas mass flow rate and temperature in the exhaust pipe downstream of the turbine for the six major running points of $\mathrm{X} 1, \mathrm{X} 2, \mathrm{X} 3, \mathrm{X} 4, \mathrm{X} 5$, and $\mathrm{X} 6$. Since the important aspect was to understand the strengths and weaknesses of each WHR system, the ORC pump and turbine speeds are altered during testing. Thus, the pump and turbine speeds were set according to literature review and benchmarking values were set, starting from $1500 \mathrm{rpm}$ reaching up to $2500 \mathrm{rpm}$ using $250 \mathrm{rpm}$ increments. The design parameters of ORC used in the simulation are presented in Table 2. 


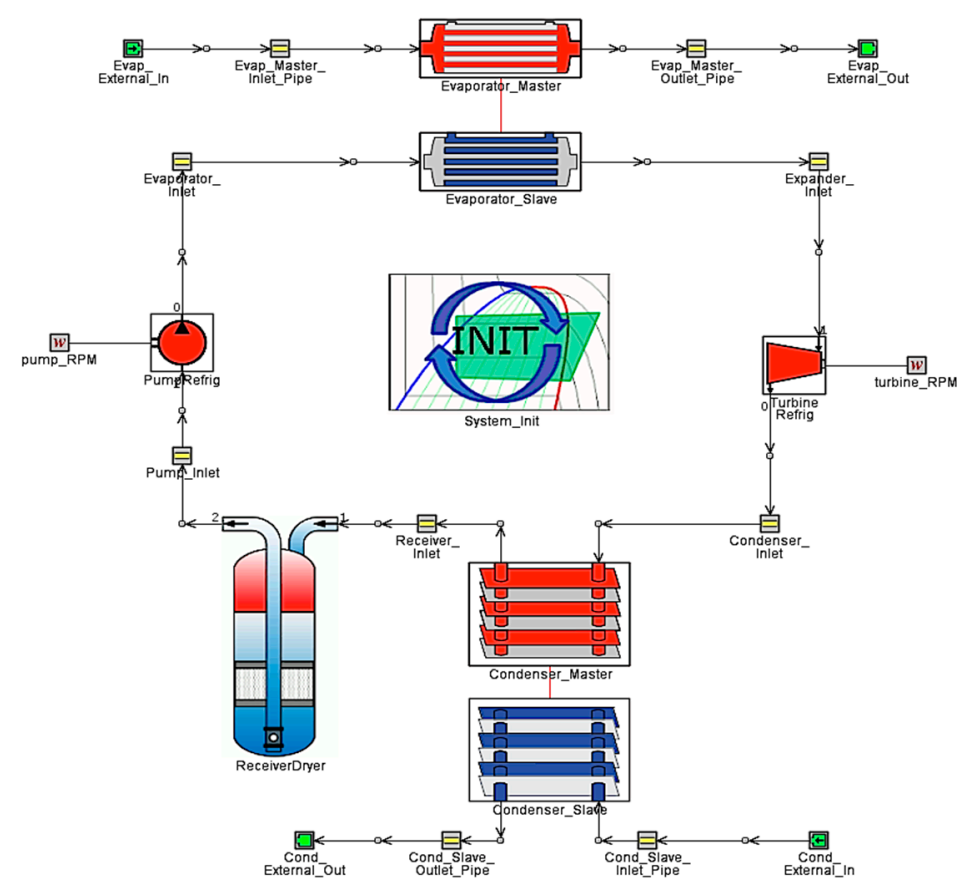

Figure 7. ORC system model in GT-Power.

Table 2. Component design parameters of ORC using R245fa refrigerant.

\begin{tabular}{|c|c|c|c|c|c|c|}
\hline \multirow[b]{2}{*}{ Design Parameters } & \multicolumn{6}{|c|}{ ORC's Main Components } \\
\hline & $\begin{array}{l}\text { Evaporator } \\
\text { (Exhaust) }\end{array}$ & $\begin{array}{c}\text { Evaporator } \\
\text { (Organic Fluid) }\end{array}$ & $\begin{array}{l}\text { Condenser } \\
\text { (Coolant) }\end{array}$ & $\begin{array}{c}\text { Condenser } \\
\text { (Organic Fluid) }\end{array}$ & $\begin{array}{l}\text { Turbine } \\
\text { Expander }\end{array}$ & Pump \\
\hline Average Inlet Pressure (bar) & 1.00102 & 24.9 & 2.15 & 3.28 & 24.3 & 2.6 \\
\hline Average Outlet Pressure (bar) & 1 & 24.3 & 2 & 2.6 & 3.28 & 24.9 \\
\hline Average Pressure Drop (bar) & 0.0010197 & 0.631 & 0.148264 & 0.674932 & - & - \\
\hline Average Inlet Temperature (K) & 973.1 & 315.8 & 296.1 & 405.1 & 445.2 & 314.1 \\
\hline Average Outlet Temperature (K) & 450.7 & 445.2 & 302.6 & 314.1 & 405.263 & 315.8 \\
\hline Average Mass Flow Rate (g/s) & 140 & 269.2 & 3394.6 & 269.3 & 0.269 & 0.269 \\
\hline $\begin{array}{c}\text { Combined Energy Rate out of } \\
\text { Fluid }(\mathrm{kW})\end{array}$ & 78.7 & -78.7 & -73.2 & 73.2 & - & - \\
\hline Average Map Pressure Ratio & - & - & - & - & 7.37 & - \\
\hline Average Efficiency (\%) & - & - & - & - & 51.61 & 61.42 \\
\hline Average Power (kW) & - & - & - & - & 5.3 & 0.75 \\
\hline Average Pressure Rise (bar) & - & - & - & - & - & 22.3 \\
\hline
\end{tabular}

\subsection{Turbocompound System Modelling}

Similar to the engine and ORC system model, the simulation of the T/C system model is performed with the aid of GT-Power software. On an industrial technicality level, the T/C system would have to be modelled on a separate template with the full extent of its integrated components. However, for this investigation and simplicity purposes, a simple secondary turbine is placed posterior to the primary turbine. In the pursuance of supervision and manipulation reasons, the turbine is incorporated with a rotational speed regulator as well as a signal output monitor. This model is a baseline calculation estimate and not a detailed representation of a T/C system. For example, the current $\mathrm{T} / \mathrm{C}$ system model arrangement does not consider mechanical or electrical losses and thus the simulation will not represent real life expectation conclusively. The level of uncertainty is particularly higher at the developmental variables of the turbine, such as the performance map, which is a necessity for the validation of the modelled $\mathrm{T} / \mathrm{C}$ system. As a result, literature review provides the essential assumptions and input specifications in order to avoid any potential errors. The model of the integrated $\mathrm{T} / \mathrm{C}$ system is displayed in Figure 8. 


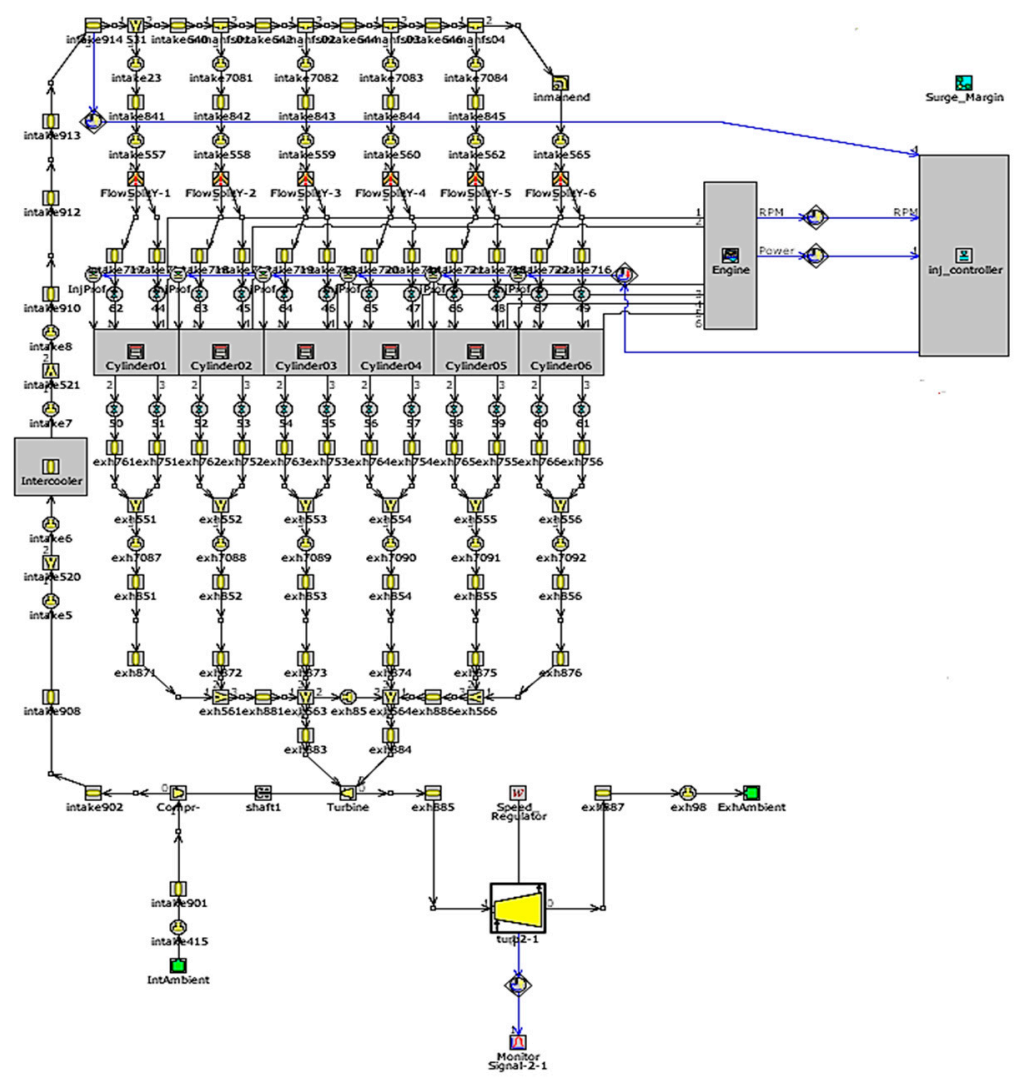

Figure 8. Turbo-compound system model.

Identically to the ORC system, benchmarking and literature review were not enough to optimize the $\mathrm{T} / \mathrm{C}$ system model and thus it has to trail a series of experimental procedures by incorporating variable parameters as a plot of trial and error. In general, the power generated by the turbine will not be linear nor at its peak for all operating conditions. Therefore, the models' turbine is assessed during diverse rotational speeds, ranging from $20,000 \mathrm{rpm}$ to $120,000 \mathrm{rpm}$ using $10,000 \mathrm{rpm}$ intervals, for all six benchmark points, resembling the process followed by the ORC system model. This will allow the identification of the optimum turbine speed for each given case and, hence, achieve maximum power output for the system as a total. The exhaust backpressure is expected to rise owing to the layout of the $\mathrm{T} / \mathrm{C}$ system, which is placed directly after the turbocharger. A rise in exhaust gas pressure translates to further engine pumping losses during the intake and exhaust strokes. A comparable ORC system will also increase backpressure in the evaporator and this effect has been studied closely and published in a dedicated paper [58] by the Brunel University team. The important assumption here was that the heat exchanger technology, which can be employed, would have a minimal impact on fuel consumption. This is not an unfair assumption in view of the availability of heat exchanger technologies available with minimum impact to the gas exchange process. For the T/C case however, backpressure is heavily dependent on the operative expansion ratio and efficiency of the turbine expander-two parameters which are captured in the present investigation.

\section{Results and Discussion}

As mentioned, an in-depth investigation is conducted to assess and compare the advantages and disadvantages of integrated T/C and ORC systems. This section will provide a thorough comprehension for the results comparison of both WHR methods. In the specific engine property, between two configurations, the BSFC value ranges from a maximum value of $298.09 \mathrm{~g} / \mathrm{kW} \cdot \mathrm{h}$ down to a minimum of $205.87 \mathrm{~g} / \mathrm{kW} \cdot \mathrm{h}$. The variation in power gains caused by the different pump and turbine speeds for the ORC and T/C systems (only the latter is varied for the $\mathrm{T} / \mathrm{C}$ as there is no pump in the 
model) is also reviewed and explained in detail. The superior WHR method will be exclaimed by the BSFC reduction percentages and flexibility in operation.

\subsection{Engine Waste Heat}

The primary engine parameter, which is responsible for the performance of the WHR systems, is the available energy after the turbocharger turbine. The harvesting of waste heat is mainly depended on the accessibility of waste energy. The exhaust mass flow rate and exhaust gas temperature of the engine define the available energy for harvesting. By recording the exhaust mass flow rate and exhaust gas temperature values, one can determine the exhaust energy at the desired points of study. In general, more efficient energy gatherings are possible during top end operation. If the power unit is working at high engine speeds, the air mass inducted by the pistons increases, followed by larger amounts of fuel injected in the cylinders. Hence, the exhaust energy is enhanced due to the rise in exhaust gas mass flow rate. Therefore, it can be stated that there is a direct correlation between available exhaust energy, exhaust gas mass flow rate, engine speed, and possibly engine power output. Figure 9 represents the mass flow rate, BMEP, and engine speed, proportionality.

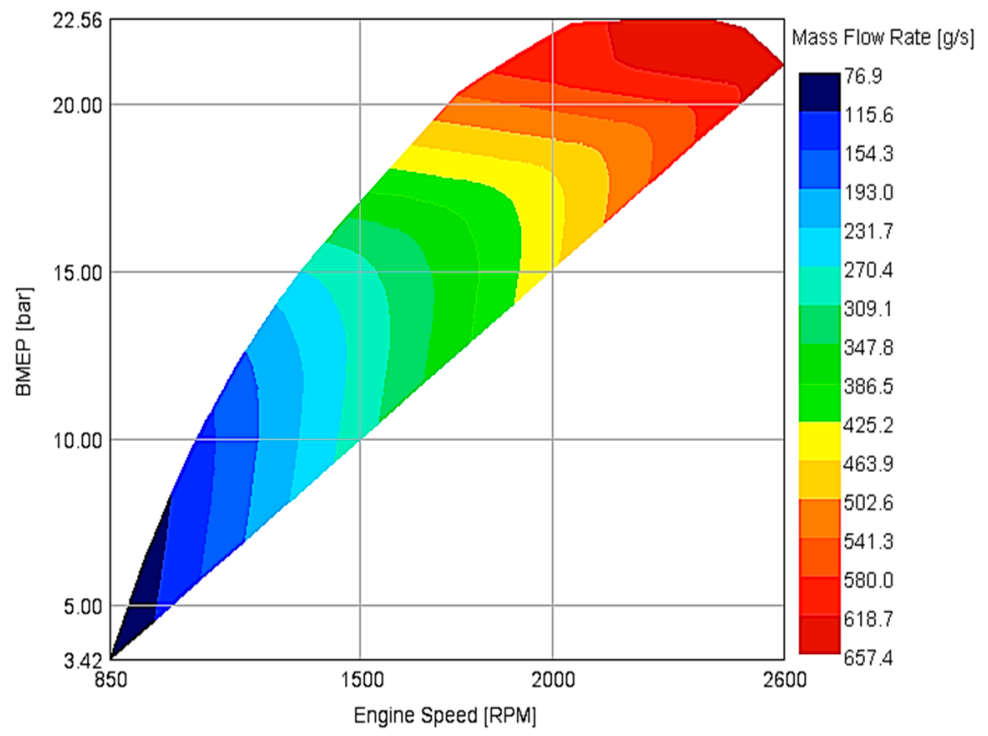

Figure 9. Variation of exhaust gas mass flow rate in accordance with engine speed and BMEP.

On the flipside, this correlation is not true for the exhaust gas temperature. In general, a high exhaust gas temperature signifies a deficient engine thermal efficiency. This is because a larger portion of energy is escaping from the combustion chamber, instead of being converted into usable mechanical work. It is observable from the contour plotting on Figure 10 that the exhaust gas temperature displays a higher temperature degree during intermediate BMEP and engine speeds. 


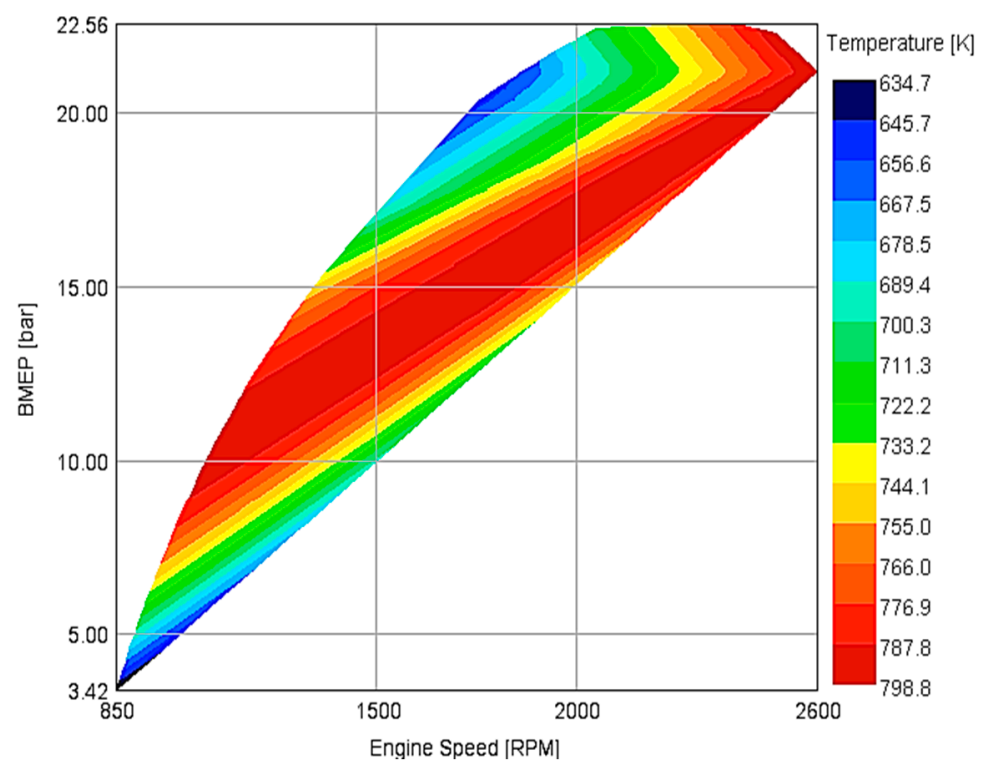

Figure 10. Variation of exhaust gas temperature in accordance with engines' speed and BMEP.

The lowest operating temperature level is achieved at the $1500 \mathrm{rpm}$ point and around $20 \mathrm{bar}$ of BMEP. This reveals the minimum BSFC value point (X2), which means that at that specific point, the engine is operating around peak thermal efficiency. Therefore, this proclaims that the exhaust temperature will predominately be higher at reduced thermal efficiencies. However, the contrast in exhaust gas temperature between the maximum and minimum thermal efficiency points is not of significant scale (approximately $160{ }^{\circ} \mathrm{C}$ ). As a result, this sets the exhaust residue mass flow rate as the primary responsibility factor of regenerated power volume. This can also be validated by comparing the exhaust gas temperature contour map against that of the thermal efficiency profile, Figures 10 and 11, respectively.

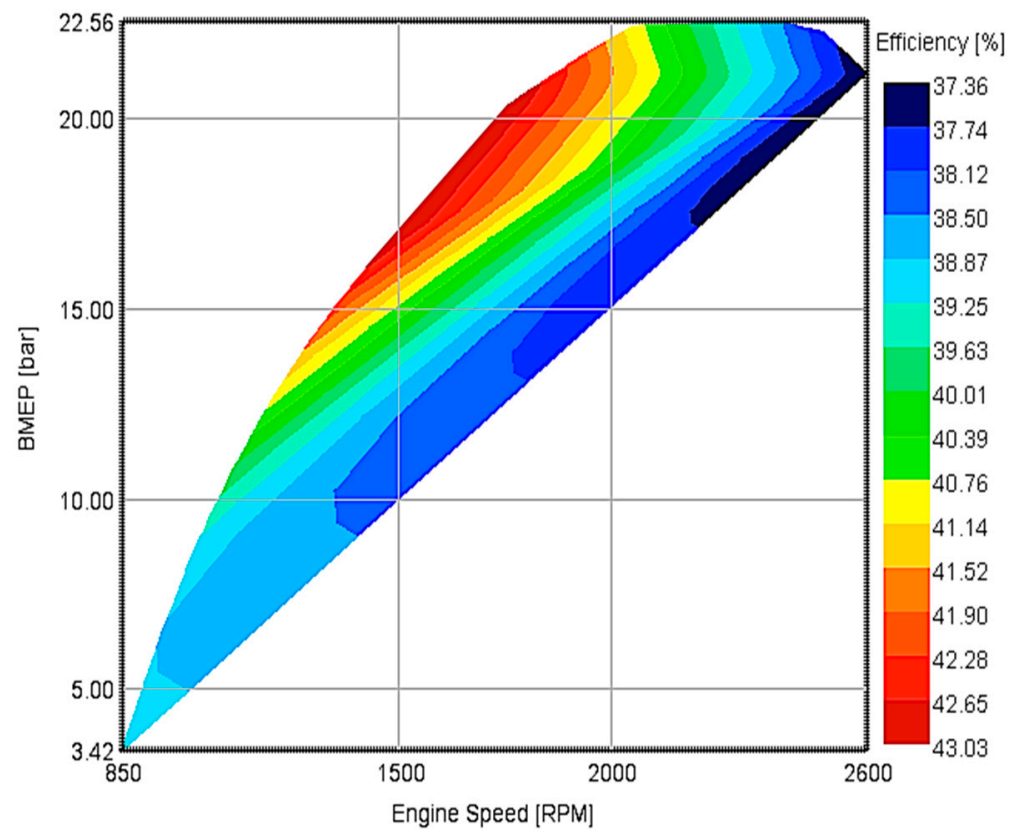

Figure 11. Variation of engine thermal efficiency in accordance with engines' speed and BMEP.

Conclusively, it can be suggested that there is a direct relation between WHR performance, engine speed, and reduced thermal efficiency profiles. This means that there is a greater potential to recover the engine's exhaust waste heat during operation at lower engine thermal efficiency. 


\subsection{Organic Rankine Cycle System}

\subsubsection{ORC System Speed Variation}

By simulating the ORC system using various pump and turbine speeds it is possible to maximize the positive characteristics for each of the six assessment points. Figure 12 represents the system speed variation to the engine test points.

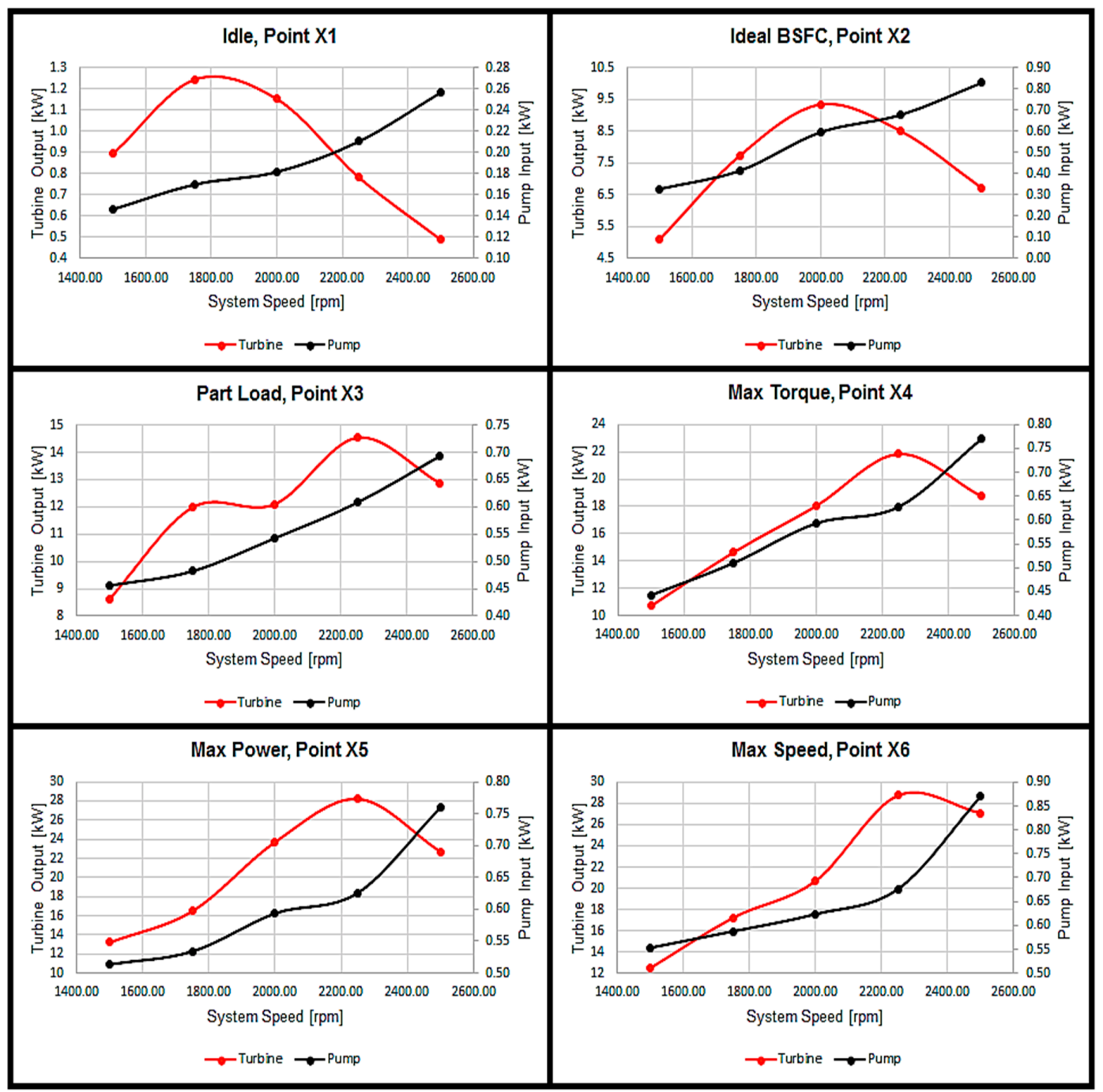

Figure 12. ORC system turbine power output in relation to system speed variation.

It is understandable that the power requirement to drive the pump increases proportionally with the pump speed. However, it is noticeable that the turbine power output fluctuates as the turbine and pump speed varies. On one hand, during the first two points $(\mathrm{X} 1, \mathrm{X} 2)$, where the engine speed and thus exhaust gas mass flow rate is mediocre, the system is productive mostly at medium to low speeds. In addition, the variation in pump and turbine speed does not seem to provoke a considerable divergence in power output across the intervals. The reason is that the power output during low engine speeds is relatively low. On the other hand, as the engine speed rises (especially at points X5 and X6) so does the exhaust mass flow rate. Therefore, the amount of waste energy available for recovery increases. This achieves a greater power acquirement per working cycle and, hence, the difference between the power output levels between the system speed intervals grows significant. Table 3 includes the total range of pump and turbine speed performance variations for the ORC system, with the maximum work input and output values highlighted in red. 
Table 3. ORC system speed variation simulations.

\begin{tabular}{|c|c|c|c|c|c|c|}
\hline & \multicolumn{2}{|c|}{$\mathrm{X} 1$} & \multicolumn{2}{|c|}{$\mathrm{X} 2$} & \multicolumn{2}{|c|}{ X3 } \\
\hline Speed & Pump & Turbine & Pump & Turbine & Pump & Turbine \\
\hline 1500 & 0.146 & 0.894 & 0.328 & 5.112 & 0.456 & 8.631 \\
\hline 1750 & 0.170 & 1.244 & 0.415 & 7.745 & 0.482 & 11.976 \\
\hline 2000 & 0.182 & 1.152 & 0.596 & 9.339 & 0.543 & 12.104 \\
\hline 2250 & 0.210 & 0.783 & 0.678 & 8.497 & 0.608 & 14.536 \\
\hline \multirow[t]{2}{*}{2500} & 0.256 & 0.490 & 0.828 & 6.723 & 0.693 & 12.863 \\
\hline & \multicolumn{2}{|c|}{$X 4$} & \multicolumn{2}{|c|}{$\mathrm{X} 5$} & \multicolumn{2}{|c|}{$\mathrm{X} 6$} \\
\hline Speed & Pump & Turbine & Pump & Turbine & Pump & Turbine \\
\hline 1500 & 0.443 & 10.710 & 0.514 & 13.211 & 0.553 & 12.479 \\
\hline 1750 & 0.510 & 14.641 & 0.534 & 16.483 & 0.588 & 17.217 \\
\hline 2000 & 0.593 & 18.040 & 0.594 & 23.712 & 0.624 & 20.687 \\
\hline 2250 & 0.628 & 21.843 & 0.626 & 28.225 & 0.676 & 28.749 \\
\hline 2500 & 0.770 & 18.740 & 0.760 & 22.686 & 0.870 & 27.081 \\
\hline
\end{tabular}

\subsubsection{ORC System BSFC Reduction}

For comparison purposes, all the calculations are conducted by utilizing the maximum values at each point. Now, BSFC is defined as the amount of fuel used per unit amount of power. By increasing power output, without increasing the fuel mass flow rate, the BSFC is reduced. Therefore, the addition of the engines' and ORC systems' power output would naturally decrease the BSFC value. Figure 13 shows the difference in BSFC.

Overall, the modelling and optimization of the ORC system managed to indicate a total average BSFC reduction of $4.78 \%$, as explained in Table 4 . The most substantial percentage value $(5.6 \%)$ occurred at maximum engine operating speed point (X6). After the introduction of the ORC system, it can be observed that $\mathrm{X} 2$ is no longer the lowest BSFC point. A $4.36 \%$ BSFC reduction at X3 was enough to shift the ideal thermal efficiency benchmark.

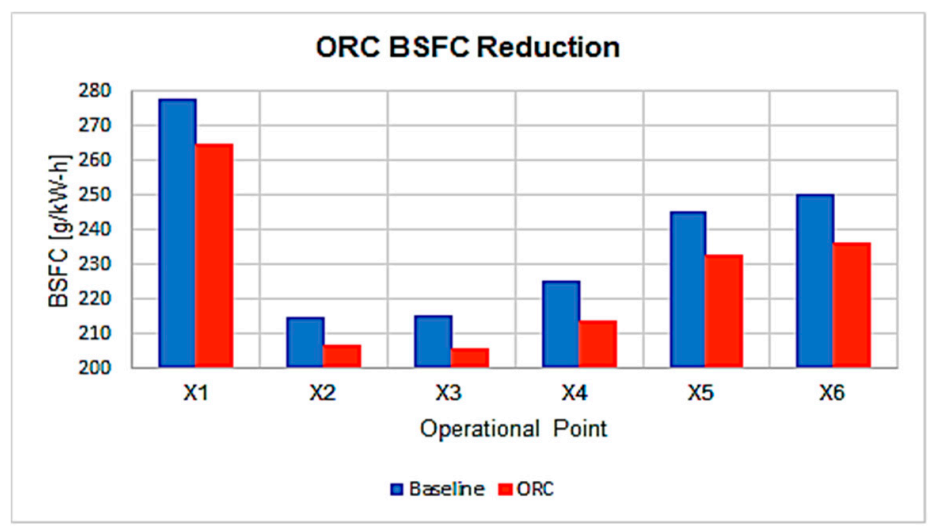

Figure 13. Reduction of BSFC in ORC system.

Table 4. Maximum BSFC reduction in ORC system.

\begin{tabular}{cc}
\hline Point & BSFC Reduction (\%) \\
\hline X1 & 4.64 \\
X2 & 3.83 \\
X3 & 4.36 \\
X4 & 5.11 \\
X5 & 5.16 \\
X6 & 5.6 \\
\hline Total & 4.78 \\
\hline
\end{tabular}

The reduction in BSFC during system operation at point $\mathrm{X} 2$ presents a value of $3.83 \%$, which is also the minimum reduction amount for the given engine. This means that the power unit at point $\mathrm{X} 2$ 
is already working at its peak thermal efficiency of approximately $43 \%$, as earlier observed in Figure 11 . Therefore, any further increments of this peak value are remarkably challenging to accomplish due to the reduced exhaust mass flow rate and temperature. Oppositely, the reason the BSFC reduction percentage is the greatest at $\mathrm{X} 6(5.6 \%)$ owns mostly to the inflated exhaust gas mass flow rate, which implements the largest impact as proved previously. Figure 14 illustrates the net power output to the BSFC reduction percentages.

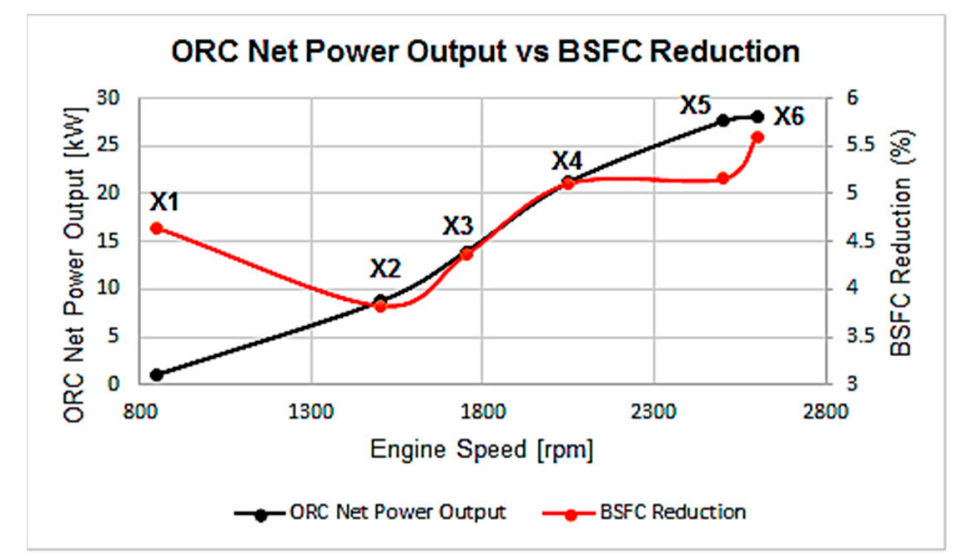

Figure 14. Variation of BSFC in accordance with ORC net power output.

The thermal efficiency of the ORC system model is plotted in Figure 15, wherein the thermal efficiency is calculated to be between $4 \%$ and $8 \%$. It is not surprising that the thermal efficiency of the ORC system ( $\left.\eta_{\text {therm }}\right)$ is at a very low mark considering that the pump and turbine were never designed to work in accordance with the specific engine exhaust outlets.

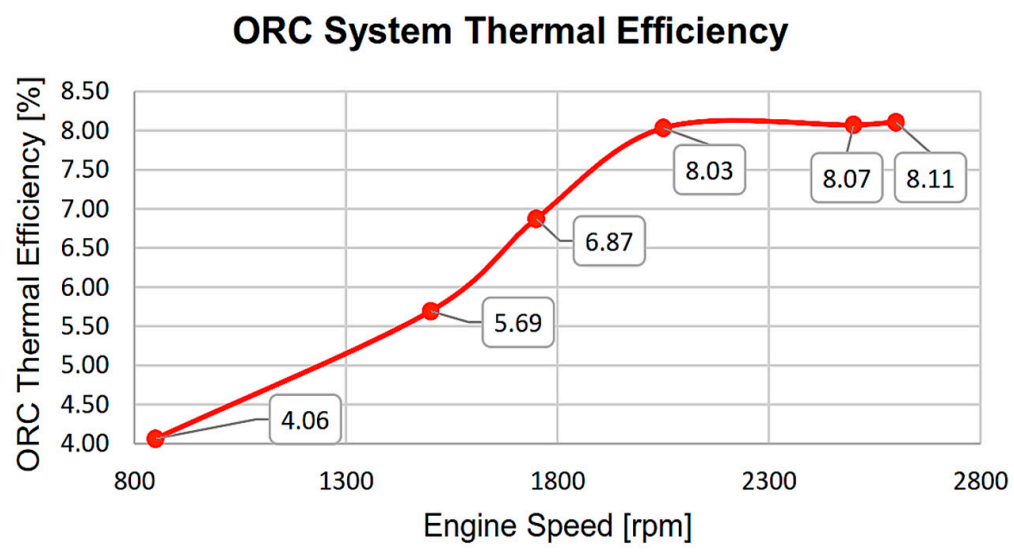

Figure 15. Thermal efficiency ORC system.

In fact, the thermal efficiency values would decrease even further. For example, if the system had not been configured as adiabatic, heat losses through the surroundings would, as a supplementary, encourage an even less efficient ORC operation. The low thermal efficiency of the ORC system contributed to the selection of the organic fluid, R245fa or any other for that matter. The decreased temperature input required for operation provokes the decrease in thermal efficiency. In the thermal efficiency graph, shown in Figure 15, there is an apparent inflation after the 2000 rpm mark. Nevertheless, despite the improved efficiency at high engine speeds, during high engine speeds and loads the ORC system is not able to take advantage of the additional and excessive amount of waste heat.

Engine efficiency can be seen to increase by a maximum of $5.69 \%$ at $1500 \mathrm{rpm}$. This is one of the speeds of interest for a heavy-duty engine, with the speed range of 1200-1500 rpm being, generally, the region of interest. The achieved efficiency compared well with engine data taken from the Brunel 
University London engine ORC test facility and reported by Alshammari et al [68], at least from the point of view of cycle efficiency (4.3\%) against a value of 4.95 to $5.69 \%$ in the region of interest in Figure 15.

\subsection{Turbo-Compound System}

\subsubsection{Turbo-Compound System Speed Variation}

Identical to the ORC systems' process, the $\mathrm{T} / \mathrm{C}$ system is run through the six operating benchmarks $(X 1, X 2, X 3, X 4, X 5$, and $X 6)$ which were defined during engine calibration. The power output of the T/C system model varies significantly with transitional turbine rotational speeds for a given operational occasion. It was revealed that the $\mathrm{T} / \mathrm{C}$ system performed diversely for bottom, mid, and top range engine speeds. Figure 16 represents the ideal turbine speed configuration for each assessment point. During low fuel, mass flow rate, and load (point X1), the turbine was more productive by operating at high speeds of over 100,000 rpm. During testing at the highest thermal efficiency (point X2) and part load (point X3), a mediocre turbine speed was ideal, showing peak performance at 60,000 rpm. However, during top end runs (points X5 and X6) it is observable that high turbine speeds achieve the best power outputs. In particular, with a turbine speed setting of 100,000 rpm during max power output and a max engine speed (points X5, X6), the T/C system generates $34.66 \mathrm{~kW}$ and $35.68 \mathrm{~kW}$ respectively. The full extent of the variable speed turbine results is listed in Table 5 . The peak turbine power outputs for each point are highlighted in red.

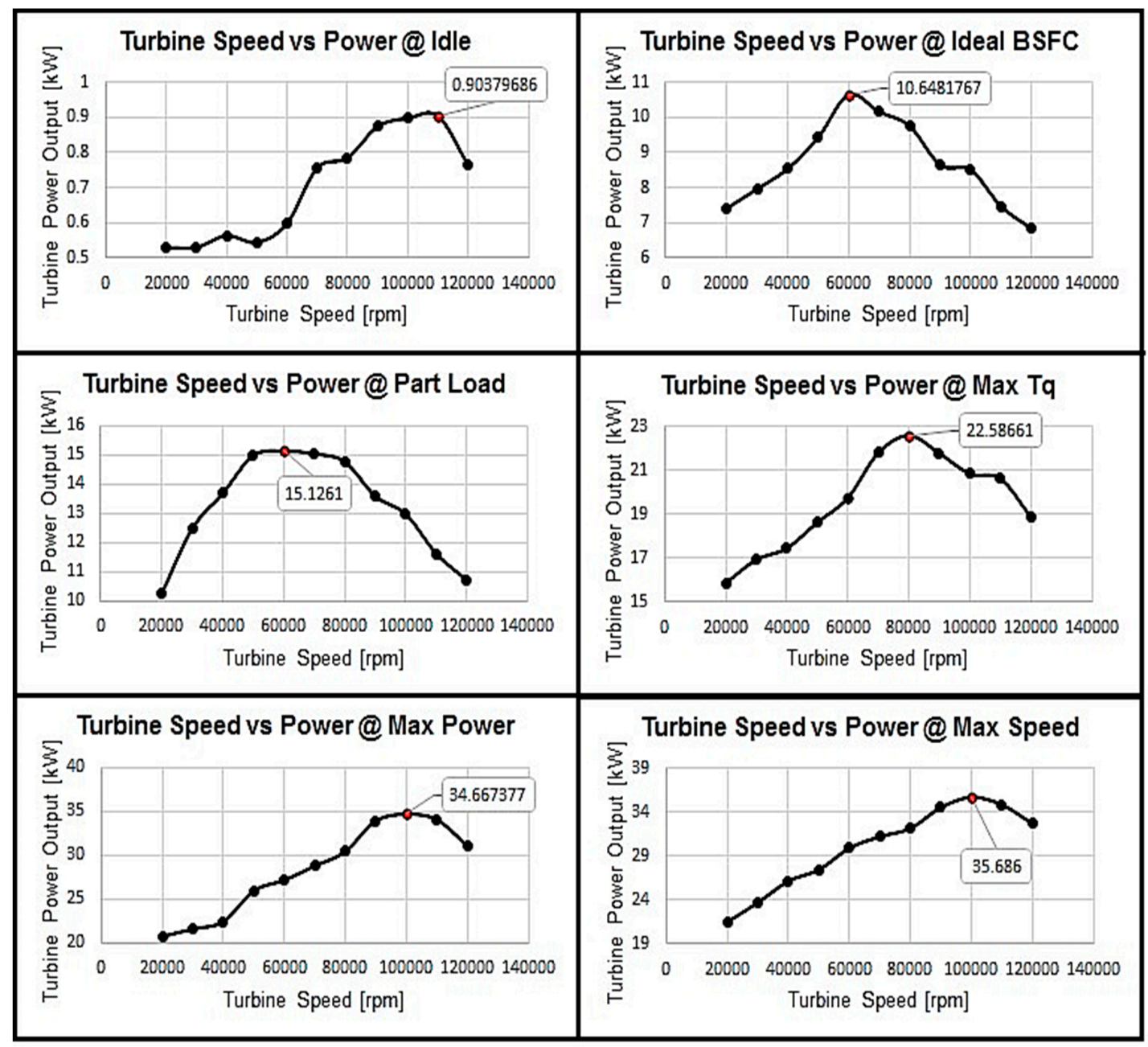

Figure 16. T/C system turbine power output in relation to turbine speed variation. 
Table 5. Turbine analytical power output to speed variation.

\begin{tabular}{ccccccc}
\hline $\begin{array}{c}\text { Turbine } \\
\text { Speed (rpm) }\end{array}$ & Idle (kW) & $\begin{array}{c}\text { Ideal BSFC } \\
\mathbf{( k W )}\end{array}$ & $\begin{array}{c}\text { Part Load } \\
\mathbf{( k W )}\end{array}$ & $\begin{array}{c}\text { Max Torque } \\
\mathbf{( k W )}\end{array}$ & $\begin{array}{c}\text { Max Power } \\
\mathbf{( k W )}\end{array}$ & $\begin{array}{c}\text { Max Speed } \\
\mathbf{( k W )}\end{array}$ \\
\hline 20,000 & 0.530 & 7.409 & 10.265 & 15.874 & 20.762 & 21.520 \\
30,000 & 0.530 & 7.964 & 12.480 & 16.933 & 21.635 & 23.719 \\
40,000 & 0.564 & 8.537 & 13.683 & 17.452 & 22.451 & 26.148 \\
50,000 & 0.544 & 9.426 & 14.973 & 18.638 & 25.976 & 27.452 \\
60,000 & 0.598 & 10.648 & 15.126 & 19.747 & 27.160 & 29.897 \\
70,000 & 0.756 & 10.156 & 15.033 & 21.805 & 28.799 & 31.211 \\
80,000 & 0.784 & 9.754 & 14.770 & 22.587 & 30.425 & 32.146 \\
90,000 & 0.874 & 8.647 & 13.589 & 21.770 & 33.916 & 34.524 \\
100,000 & 0.897 & 8.504 & 12.981 & 20.836 & 34.667 & 35.686 \\
110,000 & 0.904 & 7.468 & 11.627 & 20.620 & 34.037 & 34.827 \\
120,000 & 0.765 & 6.832 & 10.725 & 18.869 & 31.042 & 32.684 \\
\hline
\end{tabular}

\subsubsection{Turbo-Compound System BSFC Reduction}

Similar to the ORC system, the comparison purposes require the use of optimum power values, despite the fact that the yields are obtained using different turbine speeds. In addition, the BSFC difference between the baseline and turbo-compound engine is calculated. There is an important difference in the analysis of the T/C and ORC systems. The ORC system is modelled on a separate template whereas the $\mathrm{T} / \mathrm{C}$ system is placed and assessed directly on the stock engine model as an integrated unit. As explained during the simulation section, due to the incorporation of the secondary turbine, the exhaust backpressure inflated, causing additional engine pumping losses. Figure 17 shows the escalation of exhaust backpressure after the introduction of the T/C system.

\section{Exhaust Back Pressure Increase}

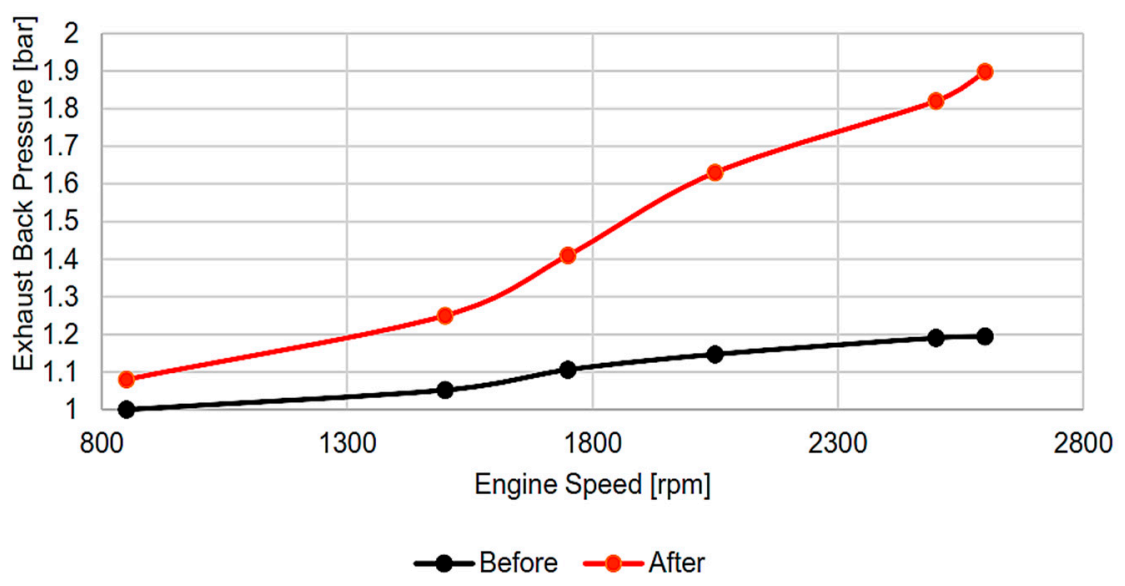

Figure 17. T/C system backpressure increment.

As expected by the increase in exhaust backpressure, the pumping losses are reflected by a proportional increase in BSFC. In fact, if the generated power output from the T/C system is not taken into account for the calculation of BSFC, the escalation in backpressure alone is enough to deteriorate the BSFC by a total average of almost $5.5 \%$ at low engine speeds. However, it is worth mentioning that this deterioration is, mostly, only distinguishable during low engine speeds, specifically as listed in Table 6 . The results show an average of $3 \%$ increase in BFSC before applying the positive aspects of the $\mathrm{T} / \mathrm{C}$ system in the standard engine model and, thus, BSFC is decreased, due to the harvested power. It is observable that this increase in BSFC is significant from point $X 1$ to point $X 3$ at an average of $5.5 \%$. On the flipside, the BSFC values for points $\mathrm{X} 4, \mathrm{X}$, and $\mathrm{X} 6$ remain identical, with an average difference of less than $0.5 \%$. This relation suggests that the higher exhaust backpressure only affects the engine 
thermal efficiency at low engine speeds. With an overall consideration, the effects of the $\mathrm{T} / \mathrm{C}$ system on the engine are represented in Figure 18.

Table 6. T/C system analytical BSFC increments.

\begin{tabular}{cc}
\hline Engine Speed (rpm) & BSFC Increase (\%) \\
\hline 850 & 6.864001 \\
1500 & 5.270832 \\
1750 & 4.345699 \\
2050 & 0.554805 \\
2500 & 0.468826 \\
2600 & 0.536313 \\
\hline Total & 3 \\
\hline
\end{tabular}

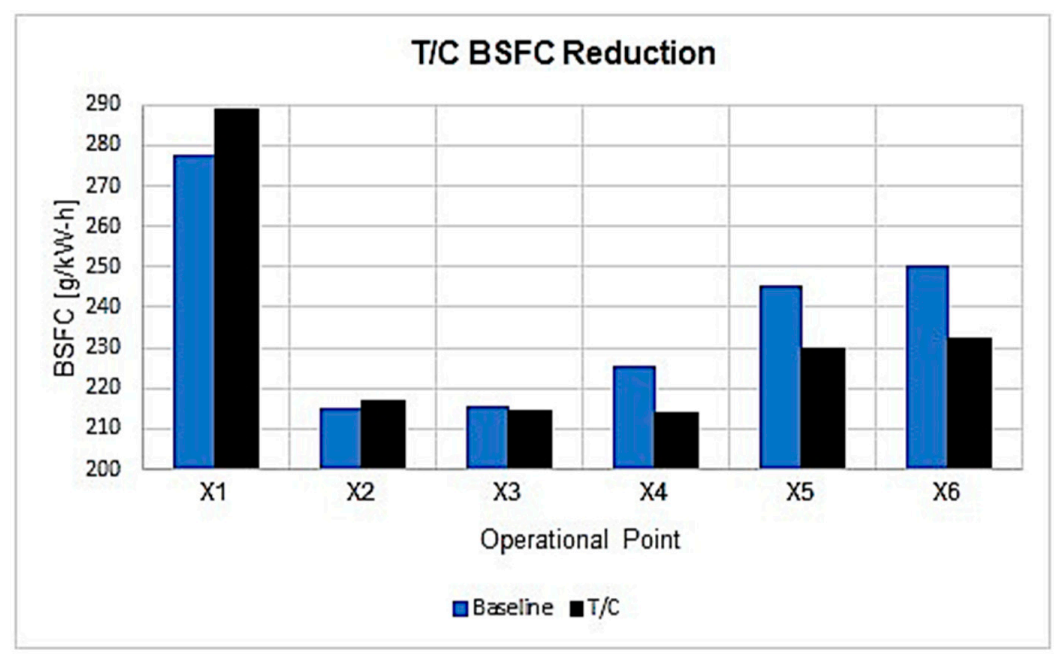

Figure 18. $\mathrm{T} / \mathrm{C}$ system BSFC reduction.

It is notable that, in excess of $2000 \mathrm{rpm}$, the effect of exhaust backpressure on BSFC was essentially annihilated. After that moment, the T/C system had the opportunity to commence with the positive characteristics of its nature. The beneficial aspects are also evident when plotting the secondary turbines' power output with the BSFC reduction percentage, plotted on Figure 19. Notice that the BSFC reduction axis has a minimum value of zero. This is done to highlight the major benefits of the $\mathrm{T} / \mathrm{C}$ system during top end operation, which touch a maximum value of $7 \%$. Table 7 includes the specific reduction values at each operational point.

Identically to the ORC system, the point of maximum engine thermal efficiency, the lowest BSFC point, is shifted to the right-hand side, namely, from the minimum point, X2 $(214.773 \mathrm{~g} / \mathrm{kW} \cdot \mathrm{h})$, to previous point of maximum torque output, $\mathrm{X} 4(213.884 \mathrm{~g} / \mathrm{kW} \cdot \mathrm{h})$. Major BSFC reductions are shown after point $X 4$, meaning that if the given engine spends most of its operating time at high speeds the $\mathrm{T} / \mathrm{C}$ system would have a theoretical reduction in BSFC at an approximate average of $6.5 \%$.

Table 7. T/C analytical BSFC reduction.

\begin{tabular}{cc}
\hline Operational Point & BSFC Reduction (\%) \\
\hline X1 & -4.02734 \\
X2 & -1.08217 \\
X3 & 0.392548 \\
X4 & 5.113118 \\
X5 & 6.355747 \\
X6 & 7.011852 \\
\hline Total & 2.293959167 \\
\hline
\end{tabular}


T/C Power Output vs BSFC Reduction

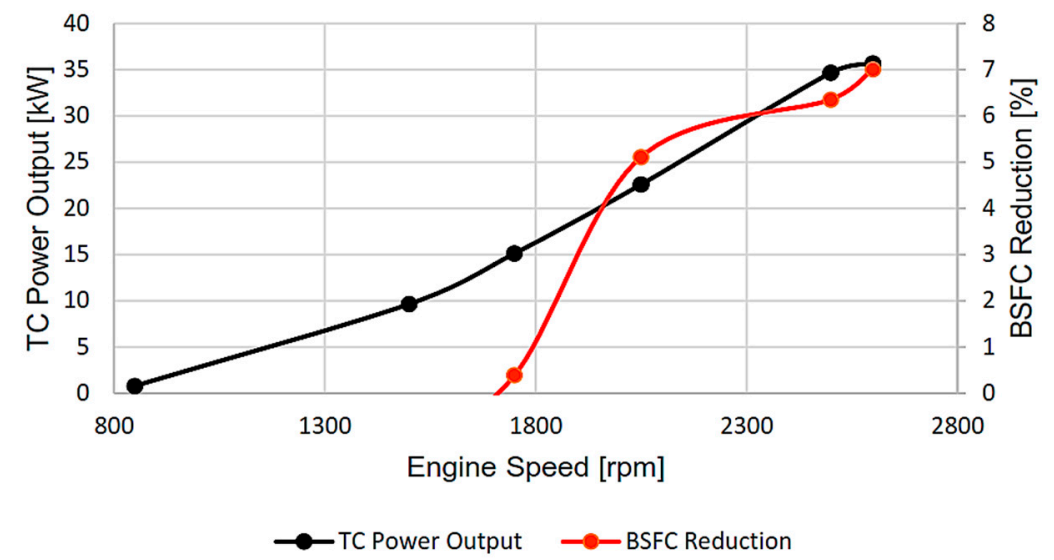

Figure 19. T/C power output vs. BSFC reduction.

\subsubsection{Turbo-Compound System Efficiency}

The thermal efficiency of the T/C system follows a similar fashion to the ORC system. Therefore, it is calculated by the amount of power gained over the exhaust energy input in the form of surplus heat. However, unlike the work input necessity for the ORC systems' pump, there was no work input required in the T/C system. As far as the exhaust energy is concerned, it was again calculated by the product of exhaust gas specific heat, mass flow rate, and temperature difference between the secondary turbines' inlet and outlet. Figure 20 illustrates the T/C systems' thermal efficiency plot.

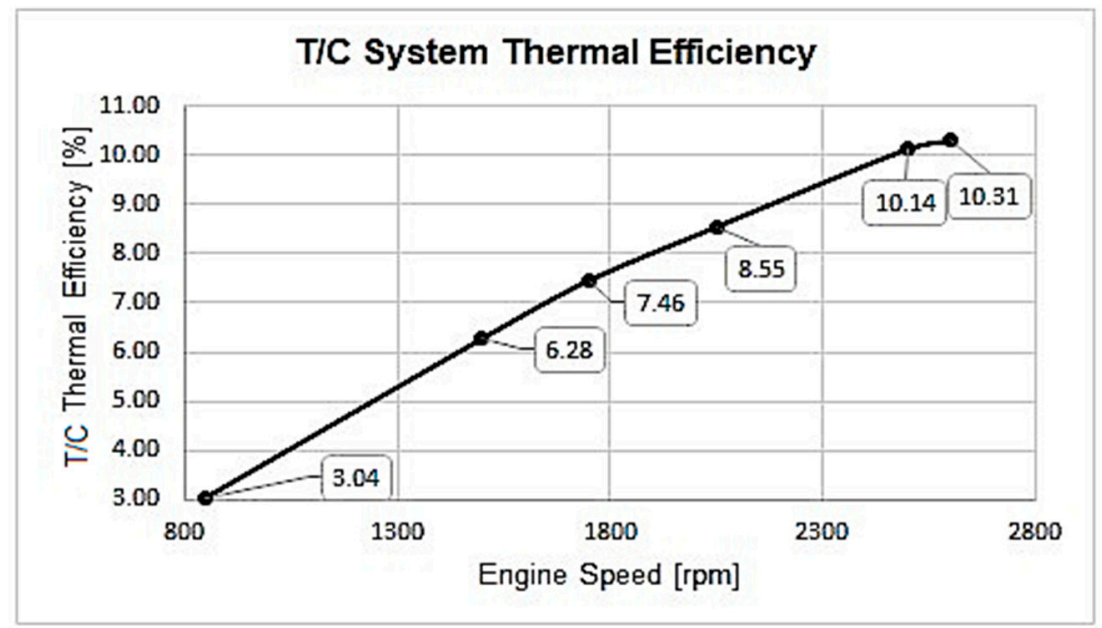

Figure 20. T/C system thermal efficiency.

A maximum of $10.31 \%$ of thermal efficiency may not seem significant, but it is heat that would otherwise be wasted. In addition, unlike the ORC system, of which the efficiency remains relatively stationary after the 2000-rpm mark, the T/C systems shows a continuously progressive increase.

\subsection{ORC T/C System vs. ORC System Comparison}

By assessing the two WHR methods individually, a solid base of strength and weakness points was set. It was noticeable that at point $\mathrm{X} 6$, which is the point for maximum engine speed, both WHR methods were at their peak BSFC reduction percentage. In fact, both produced maximum power output and reached maximum thermal efficiencies at point X6. This is due to the benchmarks' higher exhaust mass flow rate. On the other hand, the increment of exhaust mass flow rate subsequently reduced the exhaust gas temperature. As engine speed was increasing for a given engine load, fuel mass flow rate was also raised. At the same time, the compressor was forcing additional air into the cylinders. 
As a result, the combustion process improved due to the higher oxygen content within the combustion chamber, featured by the increased air mass flow rate and air to fuel ratio. The improved combustion converts the chemical energy supplied by the diesel to effective mechanical work more effectively, instead of wasting it as energy in the form of heat. However, the reduction in BSFC was naturally greater at higher BSFC values because they are susceptible to permit more room for improvement. For the same reasons, it was observed that for both the T/C and ORC systems, the lowest BSFC point is conveyed after the WHR implementations.

Despite the excessive turbulent flow that undermines the already unstable exhaust gas pulse at the measuring point (after the turbine), the temperature of the exhaust gas demonstrated an adequate stability, which further benefits the WHR methods. For a clearer contrast resolution, the BSFC values from points $\mathrm{X} 1$ to $\mathrm{X} 6$ are plotted on the same graph for both the ORC and $\mathrm{T} / \mathrm{C}$ systems while using the original plot as a gauge, as shown in Figure 21.

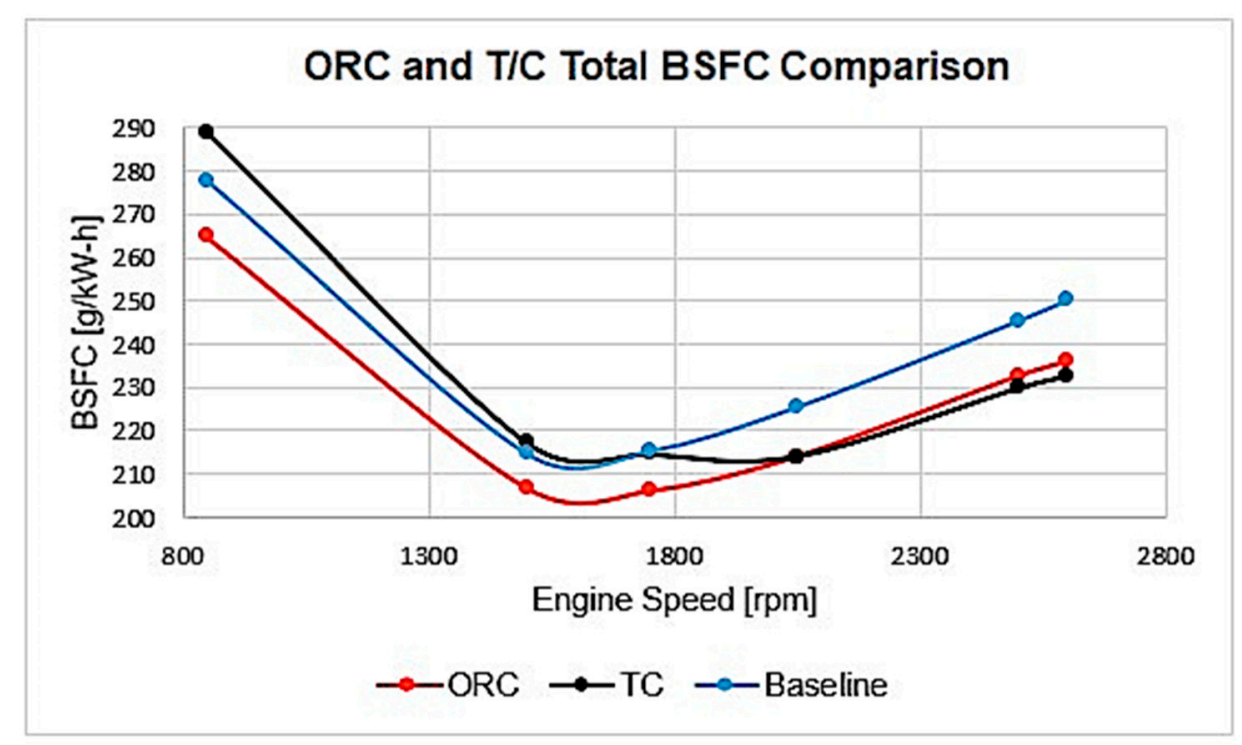

Figure 21. Comparison of total BSFC between ORC and T/C in relation to engines' speed.

The results indicated that the ORC system was more favorable during low engine speed operation. This is because the secondary turbine in the T/C system cannot produce enough mechanical power to compensate for the additional exhaust backpressure during low-end operation. However, it was a different story when the engine was running at high speed. At points $X 4, X 5$, and $X 6$, the exhaust backpressure did not have a major impact on the BSFC value. In addition, the turbine thrived, due to the increased exhaust mass flow rate, and the power gain was in excess of $35 \mathrm{~kW}$ at the finishing point. That was not only enough to compensate for the low engine speed losses, but also to further decrease the overall BSFC by an average of $2.3 \%$. The comparison of BSFC between the two WHR systems as well as the baseline engine is also visualized in Figure 22. As far as the physical mass and volume properties of the two WHR systems are concerned, both are at approximately the same level. A mechanical $\mathrm{T} / \mathrm{C}$ system would naturally result in more weight, due to the incorporated gearbox unit. 


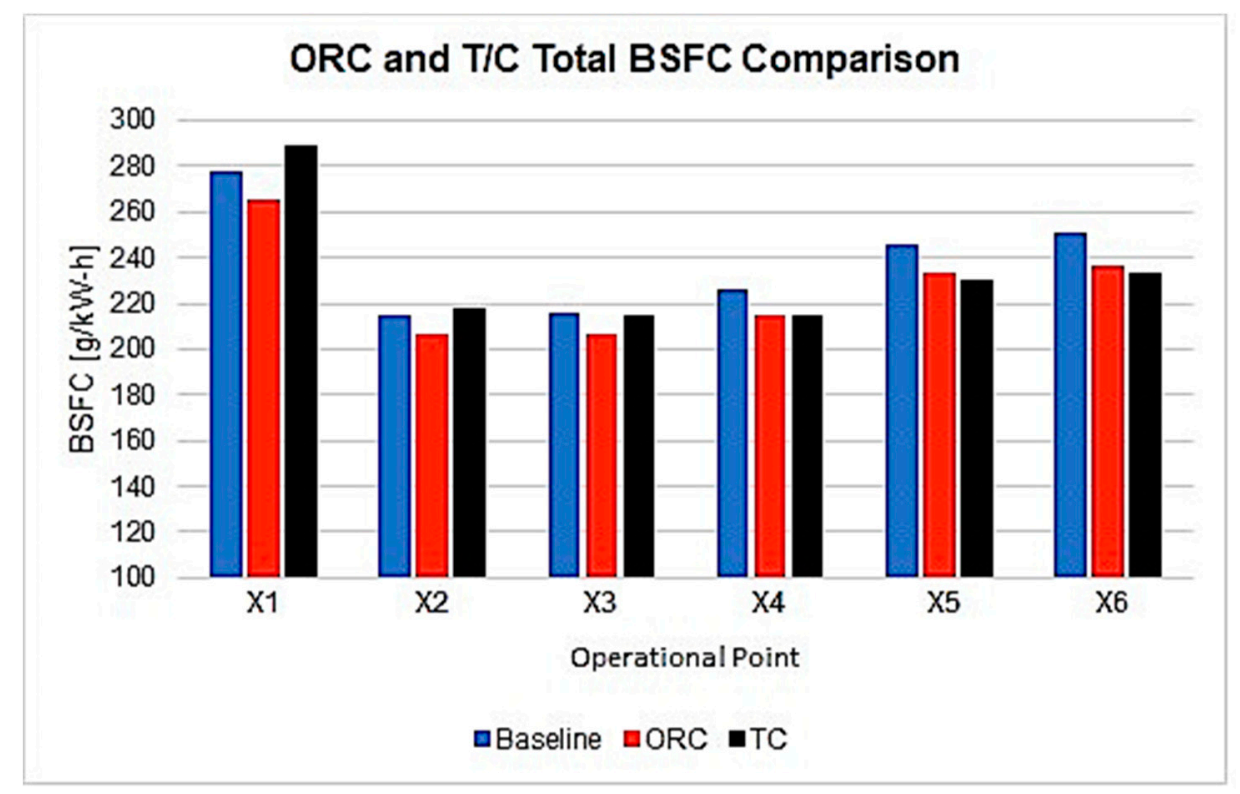

Figure 22. Comparison of total BSFC between ORC and T/C in relation to six individual points.

\section{Conclusions}

A comparison between two WHR systems using 1-D engine code simulation in GT-Power was conducted. The main aspect considered was their ability to reduce BSFC of an experimental engine model. To recapitulate, the effects of each systems' integration are listed below, as follows:

- The capability to regenerate power is determined by the availability of exhaust energy at the systems inlet conditions. That availability is reduced at ideal BSFC regions and increased during top end engine speeds.

- Exhaust energy is directly proportional to exhaust gas temperature and mass flow rate, however only the latter administers the greatest impact; temperature remains relatively unchanged across the engines' range.

- The power outputs for both WHR methods varied with the systems operational speed. The maximum power obtain by the ORC and T/C systems were $27.3 \mathrm{~kW}$ and $35.6 \mathrm{~kW}$ respectively.

- The ORC managed a total average BSFC reduction of $4.8 \%$, whereas the T/C yielded an average of $2.3 \%$.

- The thermal efficiencies of the ORC and T/C systems were considerably low, at max values of $8 \%$ and $10 \%$ respectively.

- The raise in exhaust backpressure by the T/C system affected low speed BSFC severely so much so that the system was unable to regenerate enough power to compensate for the additional fuel consumption.

The ORC system provided a more consistent WHR method, with progressive improvements in fuel consumption across the engines' speed range. However, the T/C system presents incomparable contributions in fuel economy during high-speed engine operation.

Author Contributions: A.M.A. and A.P. have written the paper context and performed the simulation works alongside the results presentation. V.E., A.S.-Z., and A.H. have carried out the design of experiment in the simulations.

Funding: This research received no external funding.

Conflicts of Interest: The authors declare no conflict of interest. 


\section{References}

1. Karvountzis-Kontakiotis, A.; Mahmoudzadeh Andwari, A.; Pesyridis, A.; Russo, S.; Tuccillo, R.; Esfahanian, V. Application of Micro Gas Turbine in Range-Extended Electric Vehicles. Energy 2018, 147, 351-361. [CrossRef]

2. Shu, G.-Q.; Yu, G.; Tian, H.; Wei, H.; Liang, X. Simulations of a Bottoming Organic Rankine Cycle (ORC) Driven by Waste Heat in a Diesel Engine (DE); SAE International: Warrendale, PA, USA, 2013.

3. Sprouse, C., III; Depcik, C. Organic Rankine Cycles with Dry Fluids for Small Engine Exhaust Waste Heat Recovery. SAE Int. J. Altern. Powertrains 2013, 2, 96-104. [CrossRef]

4. Teng, H.; Regner, G.; Cowland, C. Waste Heat Recovery of Heavy-Duty Diesel Engines by Organic Rankine Cycle Part I: Hybrid Energy System of Diesel and Rankine Engines; SAE International: Warrendale, PA, USA, 2007.

5. Yang, F.; Zhang, H.; Yu, Z.; Wang, E.; Meng, F.; Liu, H.; Wang, J. Parametric optimization and heat transfer analysis of a dual loop ORC (organic Rankine cycle) system for CNG engine waste heat recovery. Energy 2017, 118, 753-775. [CrossRef]

6. Zhang, X.; Mi, C. Vehicle Power Management; Modeling, Control and Optimization; Springer: London, UK, 2011; p. 346.

7. Mahmoudzadeh Andwari, A.; Said, M.F.M.; Aziz, A.A.; Esfahanian, V.; Salavati-Zadeh, A.; Idris, M.A.; Perang, M.R.M.; Jamil, H.M. Design, Modeling and Simulation of a High-Pressure Gasoline Direct Injection (GDI) Pump for Small Engine Applications. J. Mech. Eng. 2018, SI 6, 107-120.

8. Said, M.F.M.; Aziz, A.B.A.; Latiff, Z.A.; Mahmoudzadeh Andwari, A.; Soid, S.N.M. Investigation of Cylinder Deactivation (CDA) Strategies on Part Load Conditions; SAE Technical Paper 2014-01-2549; SAE International: Warrendale, PA, USA, 2014.

9. Yamaguchi, T.; Aoyagi, Y.; Osada, H.; Shimada, K.; Uchida, N. BSFC Improvement by Diesel-Rankine Combined Cycle in the High EGR Rate and High Boosted Diesel Engine. SAE Int. J. Engines 2013, 6, 1275-1286. [CrossRef]

10. Yang, Y.; Zhang, H.; Xu, Y.; Zhao, R.; Hou, X.; Liu, Y. Experimental study and performance analysis of a hydraulic diaphragm metering pump used in organic Rankine cycle system. Appl. Therm. Eng. 2018, 132, 605-612. [CrossRef]

11. Zhang, J.; Zhang, H.; Yang, K.; Yang, F.; Wang, Z.; Zhao, G.; Liu, H.; Wang, E.; Yao, B. Performance analysis of regenerative organic Rankine cycle (RORC) using the pure working fluid and the zeotropic mixture over the whole operating range of a diesel engine. Energy Convers. Manag. 2014, 84, 282-294. [CrossRef]

12. Zhang, X.; Zeng, K.; Bai, S.; Zhang, Y.; He, M. Exhaust Recovery of Vehicle Gasoline Engine Based on Organic Rankine Cycle; SAE International: Warrendale, PA, USA, 2011.

13. Zhou, F.; Joshi, S.N.; Rhote-Vaney, R.; Dede, E.M. A review and future application of Rankine Cycle to passenger vehicles for waste heat recovery. Renew. Sustain. Energy Rev. 2017, 75, 1008-1021. [CrossRef]

14. Bell, C. Maximum Boost: Designing, Testing and Installing Turbocharger Systems; Robert Bentley, Incorporated: Cambridge MA, USA, 1997.

15. Bin Mamat, A.M.I.; Martinez-Botas, R.F.; Rajoo, S.; Hao, L.; Romagnoli, A. Design methodology of a low pressure turbine for waste heat recovery via electric turbocompounding. Appl. Therm. Eng. 2016, 107, 1166-1182. [CrossRef]

16. Boretti, A. Improving the Efficiency of Turbocharged Spark Ignition Engines for Passenger Cars through Waste Heat Recovery; SAE International: Warrendale, PA, USA, 2012.

17. Ghanaati, A.; Said, M.F.M.; Mat Darus, I.Z.; Mahmoudzadeh Andwari, A. A New Approach for Ignition Timing Correction in Spark Ignition Engines Based on Cylinder Tendency to Surface Ignition. Appl. Mech. Mater. 2016, 819, 272-276. [CrossRef]

18. Mahmoudzadeh Andwari, A.; Aziz, A.A.; Said, M.F.M.; Esfahanian, V.; Latiff, Z.A.; Said, S.N.M. Effect of internal and external EGR on cyclic variability and emissions of a spark ignition two-stroke cycle gasoline engine. J. Mech. Eng. Sci. 2017, 11, 3004-3014. [CrossRef]

19. Mahmoudzadeh Andwari, A.; Said, M.F.M.; Aziz, A.A.; Esfahanian, V.; Baker, M.R.A.; Perang, M.R.M.; Jamil, H.M. A Study on Gasoline Direct Injection (GDI) Pump System Performance using Model-Based Simulation. J. Soc. Automot. Eng. Malays. 2018, 2, 14-22.

20. Zhou, L.; Tan, G.; Guo, X.; Chen, M.; Ji, K.; Li, Z.; Yang, Z. Study of Energy Recovery System Based on Organic Rankine Cycle for Hydraulic Retarder; SAE International: Warrendale, PA, USA, 2016. 
21. Arsie, I.; Cricchio, A.; Pianese, C.; Ricciardi, V.; De Cesare, M. Modeling and Optimization of Organic Rankine Cycle for Waste Heat Recovery in Automotive Engines; SAE International: Warrendale, PA, USA, 2016.

22. Bell, A.G. Forced Induction Performance Tuning; Haynes: Bristol, UK, 2002.

23. Cipollone, R.; Battista, D.D.; Gualtieri, A. Turbo compound systems to recover energy in ICE. Int. J. Eng. Innov. Technol. 2013, 3, 249-257.

24. Ghanaati, A.; Mat Darus, I.Z.; Farid, M.; Said, M.; Mahmoudzadeh Andwari, A. A Mean Value Model for Estimation of Laminar and Turbulent Flame Speed in Spark-Ignition Engine. Int. J. Automot. Mech. Eng. Online 2015, 11, 2229-8649. [CrossRef]

25. Mahmoudzadeh Andwari, A.; Azhar, A.A. Homogenous Charge Compression Ignition (HCCI) Technique: A Review for Application in Two-Stroke Gasoline Engines. Appl. Mech. Mater. 2012, 165, 53-57.

26. Chen, T.; Zhuge, W.; Zhang, Y.; Zhang, L. A novel cascade organic Rankine cycle (ORC) system for waste heat recovery of truck diesel engines. Energy Convers. Manag. 2017, 138, 210-223. [CrossRef]

27. Dolz, V.; Novella, R.; García, A.; Sánchez, J. HD Diesel engine equipped with a bottoming Rankine cycle as a waste heat recovery system. Part 1: Study and analysis of the waste heat energy. Appl. Therm. Eng. 2012, 36, 269-278. [CrossRef]

28. El Chammas, R.; Clodic, D. Combined Cycle for Hybrid Vehicles; SAE International: Warrendale, PA, USA, 2005.

29. Cochran, D.L. Working Fluids for High Temperature, Rankine Cycle, Space Power Plants; SAE International: Warrendale, PA, USA, 1961.

30. Mahmoudzadeh Andwari, A.; Pesiridis, A.; Esfahanian, V.; Salavati-Zadeh, A.; Karvountzis-Kontakiotis, A.; Muralidharan, V. A Comparative Study of the Effect of Turbocompounding and ORC Waste Heat Recovery Systems on the Performance of a Turbocharged Heavy-Duty Diesel Engine. Energies 2017, 10, 1087. [CrossRef]

31. Ringler, J.; Seifert, M.; Guyotot, V.; Hübner, W. Rankine Cycle for Waste Heat Recovery of IC Engines. $S A E$ Int. J. Engines 2009, 2, 67-76. [CrossRef]

32. Serrano, J.R.; Dolz, V.; Novella, R.; García, A. HD Diesel engine equipped with a bottoming Rankine cycle as a waste heat recovery system. Part 2: Evaluation of alternative solutions. Appl. Therm. Eng. 2012, 36, 279-287. [CrossRef]

33. Lodwig, E. Performance of a 35 HP Organic Rankine Cycle Exhaust Gas Powered System; SAE International: Warrendale, PA, USA, 1970.

34. Mahmoudzadeh Andwari, A.; Pesyridis, A.; Esfahanian, V.; Said, M.F.M. Combustion and Emission Enhancement of a Spark Ignition Two-Stroke Cycle Engine Utilizing Internal and External Exhaust Gas Recirculation Approach at Low-Load Operation. Energies 2019, 12, 609. [CrossRef]

35. Matthew Read, I.S. Nikola Stosic and Ahmed Kovacevic, Comparison of Organic Rankine Cycle Systems under Varying Conditions Using Turbine and Twin-Screw Expanders. Energies 2016, 9, 614. [CrossRef]

36. Mavrou, P.; Papadopoulos, A.I.; Seferlis, P.; Linke, P.; Voutetakis, S. Selection of working fluid mixtures for flexible Organic Rankine Cycles under operating variability through a systematic nonlinear sensitivity analysis approach. Appl. Therm. Eng. 2015, 89, 1054-1067. [CrossRef]

37. Allouache, A.; Leggett, S.; Hall, M.J.; Tu, M.; Baker, C.; Fateh, H. Simulation of Organic Rankine Cycle Power Generation with Exhaust Heat Recovery from a 15 liter Diesel Engine. SAE Int. J. Mater. Manf. 2015, 8, 227-238. [CrossRef]

38. Çengel, Y.A. Introduction to Thermodynamics and Heat Transfer; McGraw-Hill: New York, NY, USA, 2007.

39. Mahmoudzadeh Andwari, A.; Aziz, A.A.; Muhamad Said, M.F.; Abdul Latiff, Z. Controlled Auto-Ignition Combustion in a Two-Stroke Cycle Engine Using Hot Burned Gases. Appl. Mech. Mater. 2013, 388, 201-205. [CrossRef]

40. Pesiridis, A. Automotive Exhaust Emissions and Energy Recovery; Nova Science Publishers, Incorporated: Hauppauge, NY, USA, 2014.

41. Mahmoudzadeh Andwari, A.; Pesiridis, A.; Karvountzis-Kontakiotis, A.; Esfahanian, V. Hybrid electric vehicle performance with organic rankine cycle waste heat recovery system. Appl. Sci. 2017, 7, 437. [CrossRef]

42. Shu, G.; Zhao, J.; Tian, H.; Wei, H.; Liang, X.; Yu, G.; Liu, L. Theoretical Analysis of Engine Waste Heat Recovery by the Combined Thermo-Generator and Organic Rankine Cycle System; SAE International: Warrendale, PA, USA, 2012.

43. Tennant, D.W.H.; Walsham, B.E. The Turbocompound Diesel Engine; SAE International: Warrendale, PA, USA, 1989. 
44. Wang, E.; Yu, Z.; Zhang, H.; Yang, F. A regenerative supercritical-subcritical dual-loop organic Rankine cycle system for energy recovery from the waste heat of internal combustion engines. Appl. Energy 2017, 190, 574-590. [CrossRef]

45. Wilson, D.E. The Design of a Low Specific Fuel Consumption Turbocompound Engine; SAE International: Warrendale, PA, USA, 1986.

46. Mahmoudzadeh Andwari, A.; Aziz, A.A.; Said, M.F.M.; Latiff, Z.A. A Converted Two-Stroke Cycle Engine for Compression Ignition Combustion. Appl. Mech. Mater. 2014, 663, 331-335. [CrossRef]

47. Kolasiński, P.; Błasiak, P.; Rak, J. Experimental and Numerical Analyses on the Rotary Vane Expander Operating Conditions in a Micro Organic Rankine Cycle System. Energies 2016, 9, 606. [CrossRef]

48. Quoilin, S.; Broek, M.V.D.; Declaye, S.; Dewallef, P.; Lemort, V. Techno-economic survey of Organic Rankine Cycle (ORC) systems. Renew. Sustain. Energy Rev. 2013, 22, 168-186. [CrossRef]

49. Katsanos, C.O.; Hountalas, D.T.; Pariotis, E.G. Thermodynamic analysis of a Rankine cycle applied on a diesel truck engine using steam and organic medium. Energy Convers. Manag. 2012, 60, 68-76. [CrossRef]

50. Kölsch, B.; Radulovic, J. Utilisation of diesel engine waste heat by Organic Rankine Cycle. Appl. Therm. Eng. 2015, 78, 437-448. [CrossRef]

51. Kulkarni, K.; Sood, A. Performance Analysis of Organic Rankine Cycle (ORC) for Recovering Waste Heat from a Heavy Duty Diesel Engine; SAE International: Warrendale, PA, USA, 2015.

52. Kunte, H.; Seume, J. Partial Admission Impulse Turbine for Automotive ORC Application; SAE International: Warrendale, PA, USA, 2013.

53. Lion, S.; Michos, C.N.; Vlaskos, I.; Rouaud, C.; Taccani, R. A review of waste heat recovery and Organic Rankine Cycles (ORC) in on-off highway vehicle Heavy Duty Diesel Engine applications. Renew. Sustain. Energy Rev. 2017, 79, 691-708. [CrossRef]

54. Mahmoudzadeh Andwari, A.; Aziz, A.A.; Said, M.F.M.; Latiff, Z.A.; Ghanaati, A. Influence of Hot Burned Gas Utilization on the Exhaust Emission Characteristics of a Controlled Auto-Ignition Two-Stroke Cycle Engine. Int. J. Automot. Mech. Eng. Online 2015, 11, 2229-8649.

55. Hopmann, U.; Algrain, M.C. Diesel Engine Electric Turbo Compound Technology; SAE International: Warrendale, PA, USA, 2003.

56. Heywood, J.B. Internal Combustion Engine Fundamentals; McGraw-Hill: New York, NY, USA, 1988.

57. Nicolas Stanzel, T.S. Markus Preißinger and Dieter Brüggemann, Comparison of Cooling System Designs for an Exhaust Heat Recovery System Using an Organic Rankine Cycle on a Heavy Duty Truck. Energies 2016, 9, 928. [CrossRef]

58. Karvountzis-Kontakiotis, A.; Pesiridis, A.; Zhao, H.; Alshammari, F.; Franchetti, B.; Pesmazoglou, I.; Tocci, L. Effect of an ORC Waste Heat Recovery System on Diesel Engine Fuel Economy for Off-Highway Vehicles; SAE International: Warrendale, PA, USA, 2017.

59. Jadhao, J.S.; Thombare, D.G. Review on Exhaust Gas Heat Recovery for I.C Engine. Int. J. Eng. Innov. Technol. 2013, 2, 93-100.

60. Hountalas, D.T.; Katsanos, C.O.; Lamaris, V.T. Recovering Energy from the Diesel Engine Exhaust Using Mechanical and Electrical Turbocompounding; SAE International: Warrendale, PA, USA, 2007.

61. He, S.; Chang, H.; Zhang, X.; Shu, S.; Duan, C. Working fluid selection for an Organic Rankine Cycle utilizing high and low temperature energy of an LNG engine. Appl. Therm. Eng. 2015, 90, 579-589. [CrossRef]

62. Noora, A.M.; Putehc, R.C.; Martinez-Botasd, R.; Rajooa, S.; Romagnolie, A.; Basheera, U.M.; Sallehb, S.H.S.; Saha, M.H.M. Technologies for Waste Heat Energy Recovery from Internal Combustion Engine: A Review. In Proceedings of the International Conference on New Trends in Multidisciplinary Research \& Practice, Istanbul, Turkey, 4-5 November 2015.

63. Hsieh, J.-C.; Fu, B.-R.; Wang, T.-W.; Cheng, Y.; Lee, Y.-R.; Chang, J.-C. Design and preliminary results of a $20-\mathrm{kW}$ transcritical organic Rankine cycle with a screw expander for low-grade waste heat recovery. Appl. Therm. Eng. 2017, 110, 1120-1127. [CrossRef]

64. Shu, G.; Wang, X.; Tian, H. Theoretical analysis and comparison of rankine cycle and different organic rankine cycles as waste heat recovery system for a large gaseous fuel internal combustion engine. Appl. Therm. Eng. 2016, 108, 525-537. [CrossRef]

65. Reck, M.; Randolf, D. An Organic Rankine Cycle Engine for a 25-Passenger Bus; SAE International: Warrendale, PA, USA, 1973. 
66. Markides, O.A.; Markides, C.N. Thermo-Economic and Heat Transfer Optimization of Working-Fluid Mixtures in a Low-Temperature Organic Rankine Cycle System. Energies 2016, 9, 448.

67. Brands, M.C.; Werner, J.R.; Hoehne, J.L.; Kramer, S. Vechicle Testing of Cummins Turbocompound Diesel Engine; SAE International: Warrendale, PA, USA, 1981.

68. Alshammari, F.; Pesyridis, A.; Karvountzis-Kontakiotis, A.; Franchetti, B.; Pesmazoglou, I. Experimental Study of a Small Scale Organic Rankine Cycle Waste Heat Recovery System for a Heavy Duty Diesel Engine with Focus on the Radial Inflow Turbine Expander Performance. Appl. Energy 2018, 215, 543-555. [CrossRef]

(C) 2019 by the authors. Licensee MDPI, Basel, Switzerland. This article is an open access article distributed under the terms and conditions of the Creative Commons Attribution (CC BY) license (http://creativecommons.org/licenses/by/4.0/). 